\title{
Microbial community dynamics and coexistence in a sulfide-driven phototrophic bloom
}

\author{
Srijak Bhatnagar ${ }^{1 \dagger}$, Elise S. Cowley ${ }^{2 \dagger}$, Sebastian H. Kopf ${ }^{3}$, Sherlynette Pérez Castro ${ }^{4}$, Sean Kearney ${ }^{5}$, \\ Scott C. Dawson ${ }^{6}$, Kurt Hanselmann ${ }^{7}$ and S. Emil Ruff ${ }^{*^{*}}$ (iD
}

\begin{abstract}
Background: Lagoons are common along coastlines worldwide and are important for biogeochemical element cycling, coastal biodiversity, coastal erosion protection and blue carbon sequestration. These ecosystems are frequently disturbed by weather, tides, and human activities. Here, we investigated a shallow lagoon in New England. The brackish ecosystem releases hydrogen sulfide particularly upon physical disturbance, causing blooms of anoxygenic sulfur-oxidizing phototrophs. To study the habitat, microbial community structure, assembly and function we carried out in situ experiments investigating the bloom dynamics over time.

Results: Phototrophic microbial mats and permanently or seasonally stratified water columns commonly contain multiple phototrophic lineages that coexist based on their light, oxygen and nutrient preferences. We describe similar coexistence patterns and ecological niches in estuarine planktonic blooms of phototrophs. The water column showed steep gradients of oxygen, $\mathrm{pH}$, sulfate, sulfide, and salinity. The upper part of the bloom was dominated by aerobic phototrophic Cyanobacteria, the middle and lower parts by anoxygenic purple sulfur bacteria (Chromatiales) and green sulfur bacteria (Chlorobiales), respectively. We show stable coexistence of phototrophic lineages from five bacterial phyla and present metagenome-assembled genomes (MAGs) of two uncultured Chlorobaculum and Prosthecochloris species. In addition to genes involved in sulfur oxidation and photopigment biosynthesis the MAGs contained complete operons encoding for terminal oxidases. The metagenomes also contained numerous contigs affiliating with Myoviridae viruses, potentially affecting Chlorobi. Our data suggest a short sulfur cycle within the bloom in which elemental sulfur produced by sulfide-oxidizing phototrophs is most likely reduced back to sulfide by Desulfuromonas $s p$.
\end{abstract}

Conclusions: The release of sulfide creates a habitat selecting for anoxygenic sulfur-oxidizing phototrophs, which in turn create a niche for sulfur reducers. Strong syntrophism between these guilds apparently drives a short sulfur cycle that may explain the rapid development of the bloom. The fast growth and high biomass yield of Chlorobiaffiliated organisms implies that the studied lineages of green sulfur bacteria can thrive in hypoxic habitats. This oxygen tolerance is corroborated by oxidases found in MAGs of uncultured Chlorobi. The findings improve our understanding of the ecology and ecophysiology of anoxygenic phototrophs and their impact on the coupled biogeochemical cycles of sulfur and carbon.

Keywords: Microbial succession, Green sulfur bacteria, Prosthecochloris, Syntrophy, Brackish coastal ecosystem, Anoxygenic phototrophy, Myoviridae, Sulfur cycling, CRISPR-Cas, Resilience

\footnotetext{
* Correspondence: eruff@mbl.edu

'Srijak Bhatnagar and Elise S. Cowley contributed equally to this work.

${ }^{4}$ Ecosystems Center and J. Bay Paul Center for Comparative Molecular

Biology and Evolution, Marine Biological Laboratory, Woods Hole, MA, USA

Full list of author information is available at the end of the article
}

(c) The Author(s). 2020, corrected publication 2023 Open Access This article is distributed under the terms of the Creative Commons Attribution 4.0 International License (http://creativecommons.org/licenses/by/4.0/), which permits unrestricted use, distribution, and reproduction in any medium, provided you give appropriate credit to the original author(s) and the source, provide a link to the Creative Commons license, and indicate if changes were made. The Creative Commons Public Domain Dedication waiver (http://creativecommons.org/publicdomain/zero/1.0/) applies to the data made available in this article, unless otherwise stated. 


\section{Background}

Estuarine and coastal water bodies are dynamic and widespread ecosystems that are often characterized by the mixing of terrestrial freshwater and ocean saltwater. The resulting brackish habitats have physical and chemical characteristics that differ from those found in fresh and saltwater ecosystems [1,2]. Brackish ecosystems are often very productive and support rich microbial and macrobial communities [1]. Estuaries provide crucial ecosystem services, the most salient of which are trapping and filtering terrestrial runoffs and pollutants before they reach the oceans, coastal protection, erosion control and habitat-fishery linkages [3-6].

Estuaries harbor abundant and diverse microbial communities that are part of a complex food web. Autotrophic microbes fix carbon dioxide through photosynthesis or chemosynthesis [7-9], while heterotrophs remineralize carbon introduced to estuaries as organic matter from the oceans or land [10-12]. The decomposition of sulfur containing organic compounds through fermentation can lead to the production of sulfide in estuarine sediments [13]. Furthermore, sulfate from seawater can be reduced by sulfate respirers to elemental sulfur or sulfide [13, 14]. Sulfate introduced by the ocean and sulfide released from the sediments form gradients in the water column that cause the development of a chemocline [15]. Additionally, estuaries and coastal marshes often exhibit a halocline, i.e. a change in salinity, and the depletion of oxygen in the water column can create an oxycline $[16,17]$. Overlapping gradients, e.g. in salinity, light availability, as well as oxygen and sulfide concentration create habitats and niches that favor certain microbial communities and conversely microbial communities can affect and respond to such gradients [18-20].

Gradients of oxygen and sulfur compounds in stratified aquatic environments as well as the penetration depth of radiation offer conditions for the development of complex and stable microbial assemblages [21]. These gradients are usually divided into a surface layer rich in oxygen, an intermediate layer with decreasing oxygen and a bottom anoxic layer. The surface layer is often dominated by oxygenic phototrophic microorganism such as Cyanobacteria and algae. The anoxic layer, particularly in systems with high organic loads, provides niches for anaerobes such as sulfate-reducing bacteria [22]. In the intermediate layer, anoxygenic phototrophs use the light from the surface and the sulfide from the bottom layers [23]. The biogeochemical processes leading to stratification in phototrophic blooms are relatively well understood [24], yet ecological niches, microbial interactions and community dynamics are less well constrained.

The abiotic and biotic drivers of stratified estuarine environments can fluctuate frequently and rapidly as a result of tidal cycles, weather events, and seasonal cycles [25-30]. Such fluctuations can cause noticeable changes in the microbial community structure of an ecosystem. It has been shown that estuarine communities are structured by salinity [31-34], precipitation [32, 35], temperature $[33,34]$, oxygen $[35,36]$ and also seasonal changes [34]. Community shifts included changes in phytoplankton populations with salinity [31], declining populations of Rhodobacterales with decreasing salinity [35], declining populations of phototrophic "Candidatus Aquiluna" with decreasing oxygen concentration, as well as general changes in the richness and evenness of the community [31-36].

Trunk River lagoon in Falmouth, MA, is a brackish ecosystem, on the coast of Vineyard Sound (N 41.535236, W-70.641298). Storms, tides, and run-off introduce large amounts of biomass forming thick layers of decaying seagrass and other organic matter. The lagoon has a sulfidic odor and emanates gases formed in the organic matter deposits. Bright yellow microbial blooms can be observed occasionally just below the water surface (see Fig. 1, Additional file 1: Figure S1), forming and disappearing within days to weeks. Transient blooms were observed to occur in natural depressions in the decaying organic matter and were apparently initiated by physical disturbance events, potentially from storms, tidal extremes, human activity, or animals. Given this natural ecological progression, we tested whether experimentally induced physical disturbance could trigger bloom formation, and whether the established blooms could be used as a model system to investigate the microbial ecology and ecophysiology of sulfur-oxidizing phototrophs.

We mimicked physical disturbances of the brackish ecosystem by creating artificial depressions in the decaying organic matter, and monitored the microbial community response and population dynamics, as well as ecological niches of the key populations. Based on the above described observations of thick layers of decaying organic matter and naturally occurring, rapid blooms of phototrophs, we hypothesize that i) the disturbance would release sulfide from the sediment and cause a sulfide-driven phototrophic bloom, ii) due to its rapid development the bloom would likely be dominated by very few populations, and iii) steep physicochemical gradients would establish creating (transient) anoxic habitats in the water column analogous to blooms in stratified lakes. The remarkably reproducible community assembly and succession provides insights into niches and coexistence of phototrophic microorganisms in a small scale ecosystem. Our findings contribute to the understanding of the ecological processes and dynamics in phototrophic blooms, which are naturally occurring phenomena in many ecosystems. 


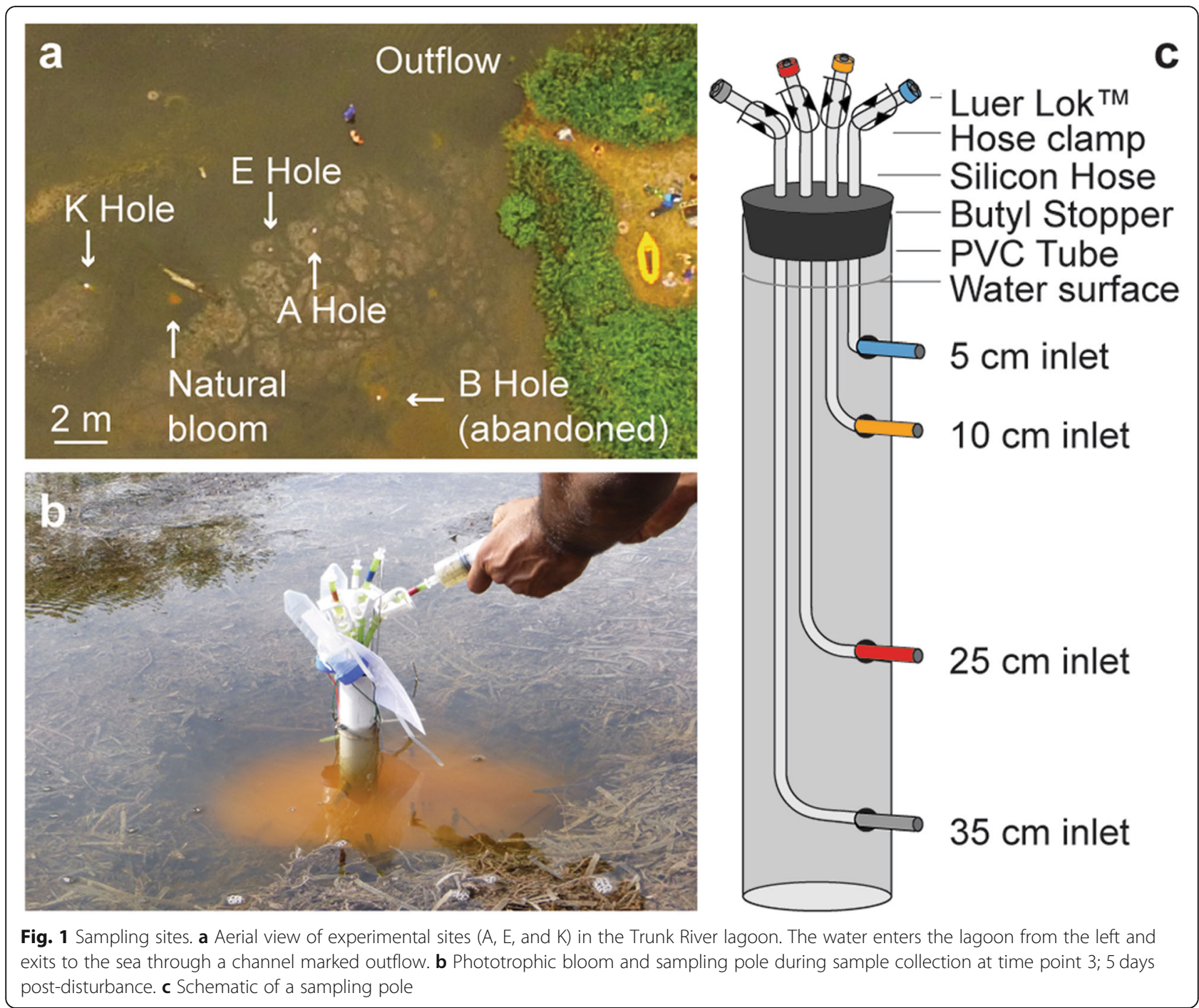

\section{Results}

This study was designed to investigate microbial community assembly, community turnover and syntrophic interactions in a sulfide-driven phototrophic bloom. To gain insights into the microorganisms niches and potential key metabolisms we studied the physicochemistry of the water column, the diversity of photopigments, and performed amplicon and metagenomic sequencing.

\section{Physicochemistry of the water column}

At the first sampling time point (two days post-disturbance), no difference in color was observed in the water column. Two days later, a faint pink layer was observed in the water column, and faint shades of yellow appeared in samples from $25 \mathrm{~cm}$ depth (Additional file 1: Figure S2, Supplementing Results). The yellow color of the suspension was most intense from timepoint 4 to 7 and had almost disappeared by timepoint 8 . Within the first three days of the experiment the $\mathrm{pH}$ decreased between one and two units in all layers, with lowest values present in the deepest layer (Fig. 2). Over the 15-day sampling period, $\mathrm{pH}$ showed more variation in the two upper layers than in the two deeper layers where it was very constant at values between $\mathrm{pH} 6$ to 6.3. Throughout the experiment the water column in all three experiments had a stable halocline with brackish water $(5 \%$ salinity) at the water surface and saltwater $(30 \%)$ at $35 \mathrm{~cm}$ depth (Fig. 2). Salinity increased with depth and was $12 \%$ and $23 \%$ at $10 \mathrm{~cm}$ and $25 \mathrm{~cm}$, respectively. Major ions also reflect this trend (e.g. calcium, potassium in Additional file 1: Figure S6). The dissolved oxygen (DO) concentrations showed a relatively stable oxycline between 10 and $25 \mathrm{~cm}$. At $10 \mathrm{~cm}$ and above, DO was mostly higher than $50 \mu \mathrm{M}$ $(91 \pm 45 \mu \mathrm{M})$ corresponding to $\sim 20 \%$ oxygen saturation (36 $\pm 17 \%$ ). At 25 and $35 \mathrm{~cm}$ DO was mostly below $50 \mu \mathrm{M}$ $(23 \pm 18 \mu \mathrm{M})$, hence below $20 \%(9 \pm 9 \%)$ saturation. The oxygen concentration slowly decreased in the upper two layers during the first half of the experiment but recovered to the initial values towards the end of the experiment. At 5 


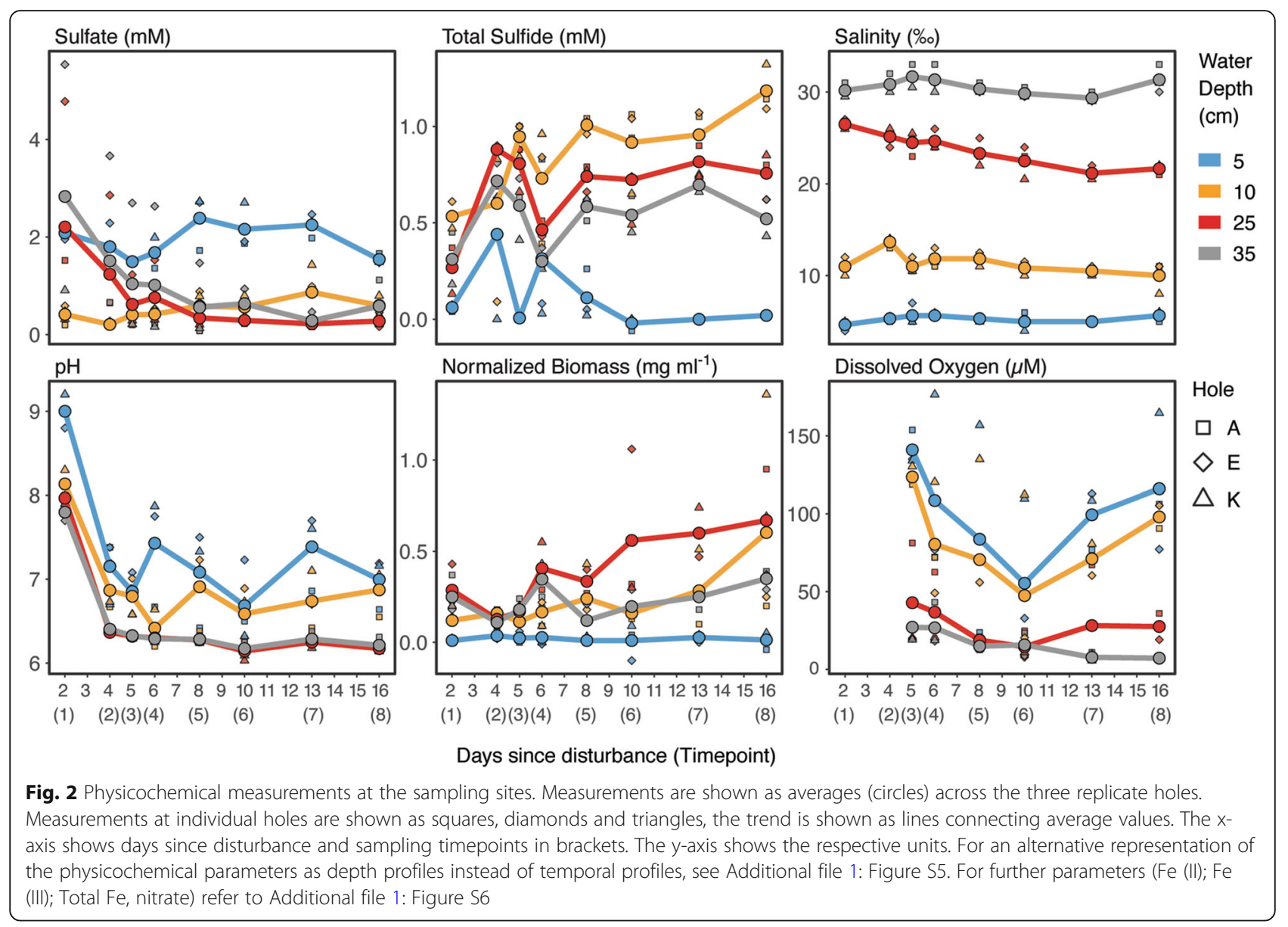

and $10 \mathrm{~cm}, \mathrm{DO}$ averaged over the experiment was $101 \pm$ $47 \mu \mathrm{M}$ and $81 \pm 41 \mu \mathrm{M}$, respectively (Fig. 2). At 25 and 35 $\mathrm{cm}$, the average DO was $28 \pm 22 \mu \mathrm{M}$ and $17 \pm 11 \mu \mathrm{M}$, respectively. The sulfate concentrations in the water column decreased along the depth gradient, with the highest sulfate concentration at $5 \mathrm{~cm}(\approx 2 \mathrm{mM})$ and the lowest at $25 \mathrm{~cm}(\approx$ $0.2 \mathrm{mM}$ ) (Fig. 2). In contrast, the sulfide concentrations were lowest at $5 \mathrm{~cm}$ (Fig. 2f). Interestingly, the greatest sulfide concentration was measured at $10 \mathrm{~cm}$ depth peaking at over $1 \mathrm{mM}$ towards the end of the experiment. Below $10 \mathrm{~cm}$, sulfide concentration was still high, but declined to $0.75 \mathrm{mM} \pm$ 0.22 at $25 \mathrm{~cm}$ and $0.5 \mathrm{mM} \pm 0.17$ at $35 \mathrm{~cm}$. The normalized biomass measured for the $5 \mathrm{~cm}$ samples throughout the sampling period was nearly zero (Fig. 2). At $10 \mathrm{~cm}, 25 \mathrm{~cm}$, and $35 \mathrm{~cm}$, the normalized biomass measured was approximately, $0.2,0.3$, and $0.2 \mathrm{mg} \mathrm{ml}^{-1}$, respectively. For details concerning iron ( $\mathrm{Fe}(\mathrm{II}), \mathrm{Fe}(\mathrm{III})$, total $\mathrm{Fe})$, nitrate, calcium, potassium, ammonium and acetate refer to Additional file 1: Supplementary Results and Figure S6. Overall, the measurements revealed stable and reproducible physicochemical gradients that divided the previously homogenous water column into layers with different redox conditions and energy availability.

\section{Spectral absorbance of phototrophic community}

We measured absorbance spectra from filters of samples from experiment A, E and K (Fig. 3a) and compared the spectra to those of representative cultured species of phototrophic genera from the literature [37-41] (Fig. 3b). Our results suggest that pigments belonging to PSB, indicated by purple vertical bands (Fig. 3a), were abundant in the upper layer of the bloom (orange spectra in Fig. 3a) especially between day 10 and 13. GSB pigments, indicated by a green vertical band, dominated the lower layers of the bloom (red and gray spectra) starting at day 10. Pigments characteristic for Cyanobacteria (brown vertical band) were less abundant in the bloom but increased at the end of the experiment relative to the PSB and GSB peaks. This suggests a minor role of Cyanobacteria initially and during the bloom but a more important role upon return to equilibrium. Pigments present in all major phototrophic lineages were detected throughout the experiment (gray vertical band). The results of the spectral analysis suggest the coexistence of multiple phototrophic lineages over the entire duration of the experiment. 


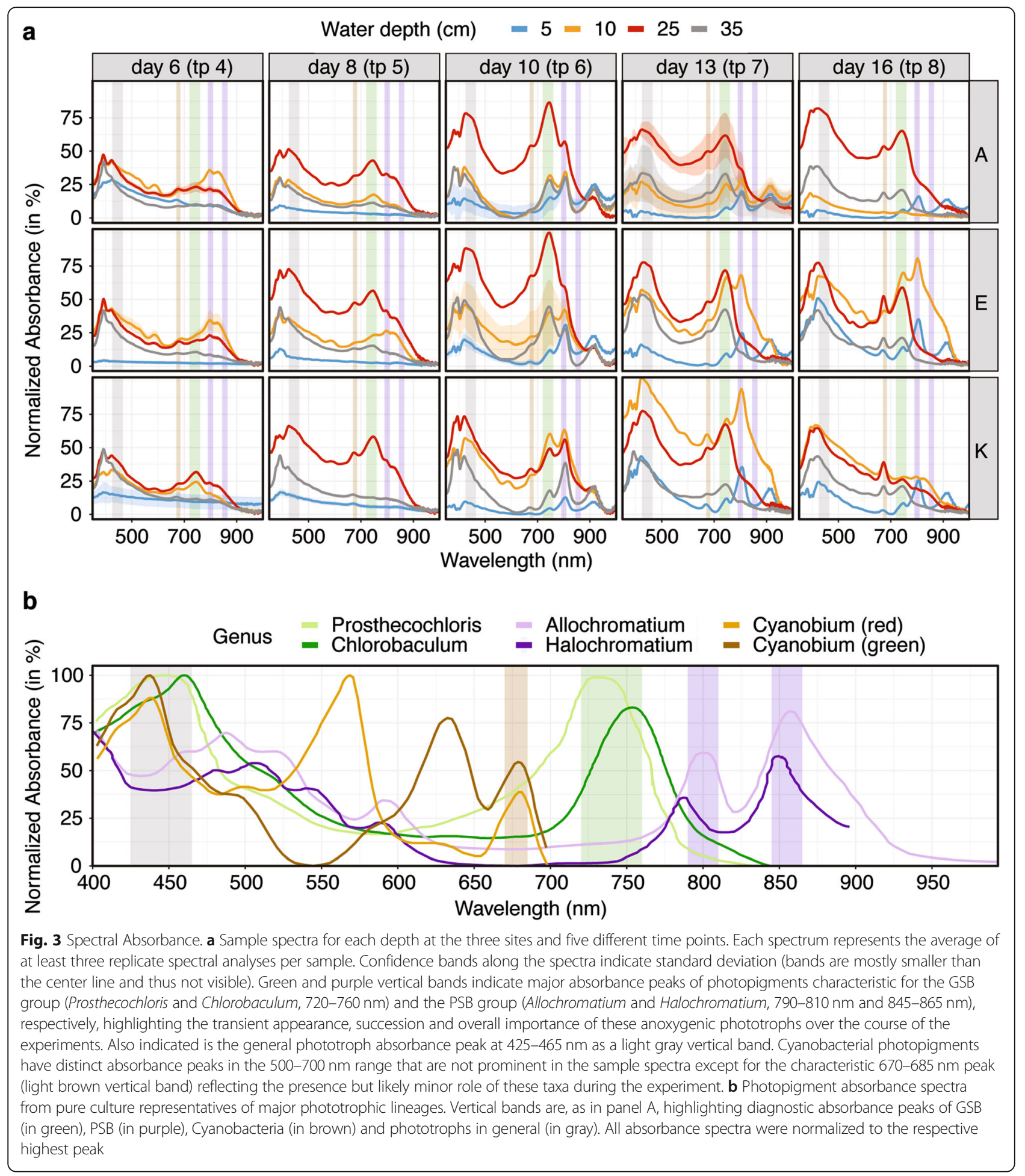

\section{Microbial community structure and taxonomic composition}

At the beginning of the experiment, the microbial diversity was high in all four water depths and very similar across replicate ecosystems. Alpha diversity rapidly decreased with the onset of the bloom, and within two days the communities in the four depth layers substantially changed (Figs. 4 and 5, Additional file 1: Figure S7, S8). The bloom occurred between 10 and $25 \mathrm{~cm}$ water depth (Additional file 1: Figure S2) with highest cell 


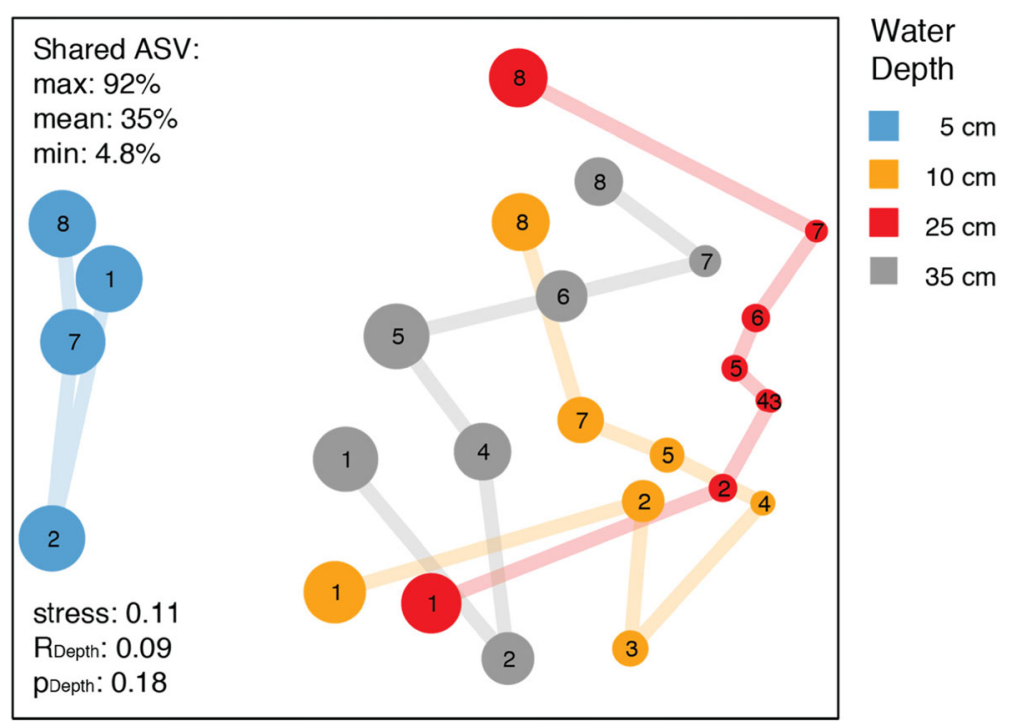

Fig. 4 Microbial Community Turnover. Non-metric multidimensional scaling (NMDS) ordination based on relative abundance of ASVs (amplicon sequence variants). Each circle represents one sample, the closer two samples are the more similar is their microbial community structure. Circle size represents Shannon Diversity. Numbers indicate sampling time points. Colors indicate bloom layers. Note: Individual holes were very similar (see Additional file 1: Figure S9A) and thus we averaged relative ASV abundances for clarity, i.e. each circle represents an average across replicate experiments. NMDS ordinations for individual experiments are shown in Additional file 1: Figure S8. The communities in the different layers of individual experiments are significantly different, yet overlapping (see Additional file 1: Figure S8)

numbers (peaking at $>10^{8}$ cells $\mathrm{ml}^{-1}$ ) and biomass at around $25 \mathrm{~cm}$ water depth (Fig. 2, Additional file 1: Figure S4) in brackish, mildly acidic, and hypoxic waters (Fig. 2). The number of observed amplicon sequence variants (ASVs), as well as estimated richness, Shannon entropy, and Inverse Simpson diversity significantly decreased between the surface water and the water at a depth of $10 \mathrm{~cm}$ and $25 \mathrm{~cm}$ (Fig. 5; $p=0.001$ ). This change is most striking in the case of Inverse Simpson diversity, a measure for evenness. In just 1 day, evenness dropped in both 10 $\mathrm{cm}$ and $25 \mathrm{~cm}$ water depth by over one order of magnitude to low single digit values (Additional file 1: Table S1). This means the community was dominated by one ASV (a pure culture has an Inverse Simpson diversity index of 1). This decrease in diversity was accompanied by a substantial decrease in $\mathrm{pH}$, as well as an increase in sulfide concentration.

The substantial change in alpha diversity is corroborated by a high turnover of ASVs between the layers and timepoints (Fig. 4, Additional file 1: Figure S8). The top layer is well separated from the deeper layers. The communities at $25 \mathrm{~cm}$ water depth experienced the largest turnover, i.e. change in community structure, and showed a loss in diversity during the experiment that seemed to have recovered at the last time point (Fig. 4). The communities of all three deep layers $(10-35 \mathrm{~cm})$ had a similar community structure at the beginning of the experiment. Interestingly, during the course of the experiment the community structure of each layer followed a different trajectory, yet at the end converged again. The trajectories of layer $2-4$ indicate that the bloom shifted the microbial communities in these layers to an alternative stable state.

The taxonomic composition was assessed at all phylogenetic levels (Additional file 1: Figure S9B). We observed a total of 73 bacterial phyla. The surface community ( 5 $\mathrm{cm})$ remained relatively unchanged throughout the experiment and was dominated by Proteobacteria, Chlorobi, Cyanobacteria and Actinobacteria. The communities in the deeper oxygen poor and sulfide rich zones $(10-35 \mathrm{~cm})$ were more dynamic, being dominated by Bacteroidetes, Proteobacteria, Firmicutes, and Chloroflexi. In general, taxonomic diversity was highest in the deepest layer (35 $\mathrm{cm})$. The observed change in microbial diversity was accompanied by a change in community composition. Within a few days, there was a substantial increase in the abundance of Chlorobi, which comprised more than $75 \%$ of the community at that time. This increase persisted for nine days, but levelled off at the end of the experiment. The datasets of all layers and timepoints were dominated by ASVs affiliating with phototrophic organisms, as shown by relative sequence abundances on genus level (Fig. 6a). Some phototrophs occurred in all layers at similar relative sequence abundances, such as Halochromatium and "Candidatus Chloroploca". The stable surface layer harbored Cyanobium and "Candidatus Aquiluna", which decreased in the deeper layers. The upper layer of the bloom showed an increased relative sequence abundance of Allochromatium, the lower bloom layer was dominated by 

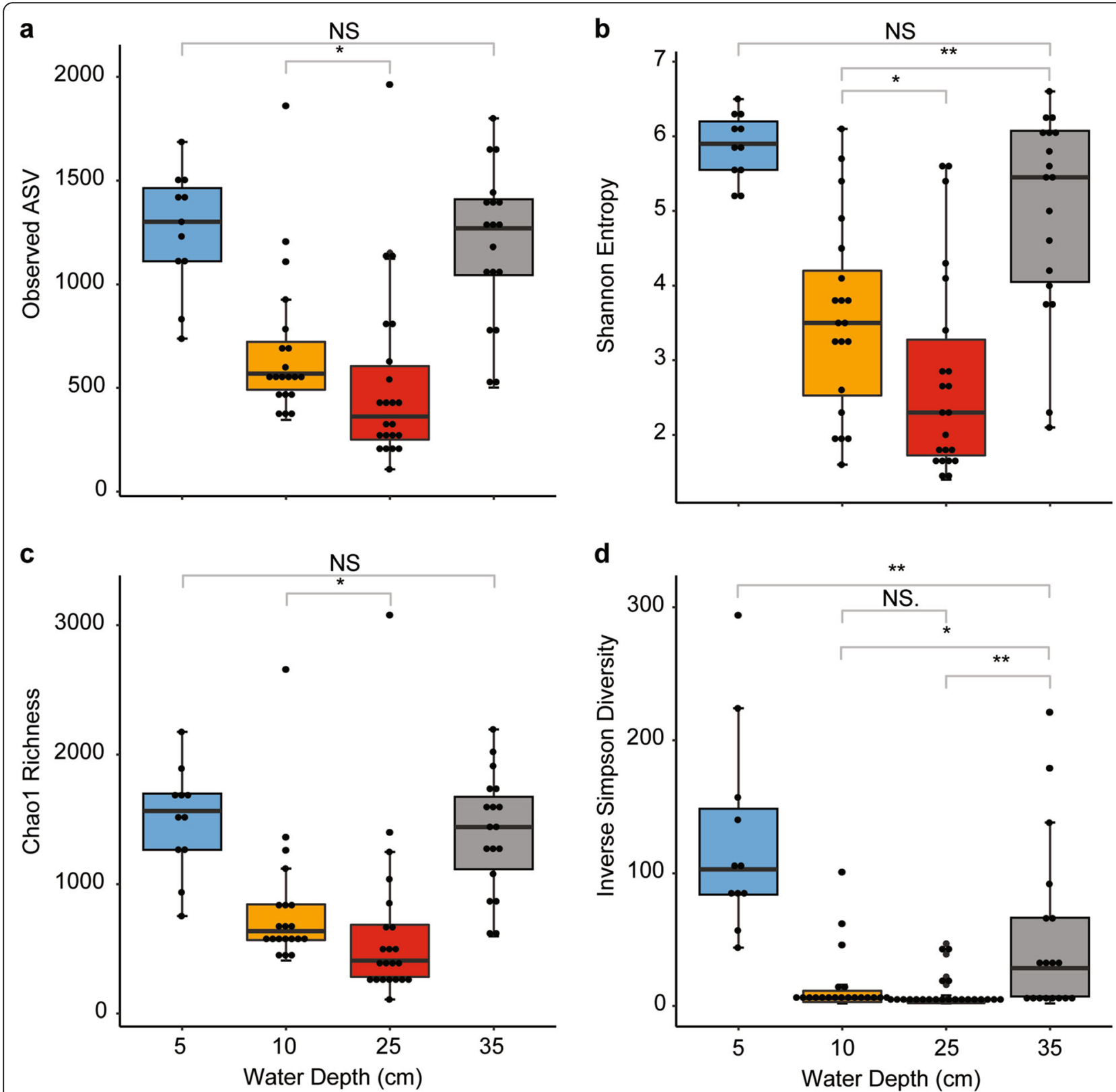

Fig. 5 Diversity Indices of all samples grouped by depth. a Richness is shown as the number of observed amplicon sequence variants (ASVs). Richness gives equal weight to all ASVs regardless of their abundance. b Shannon entropy considers ASV richness and proportional abundance, $\mathbf{c}$ Chao1 richness represents an estimate of the total number of ASVs that may be present in the sample. $\mathbf{d}$ Inverse Simpson diversity considers ASV richness and proportional abundance, similar to Shannon entropy, but gives additional weight to proportional abundance (evenness). All indices show significantly lower diversity in the bloom layers, especially at $25 \mathrm{~cm}$ depth, as compared to the top and bottom layers. Diversity indices were calculated using a subsampling approach to account for unequal sampling effort. Pairwise comparisons with low significance levels are shown (NS, $\left.{ }^{*}: p<0.1,^{* *}: p<0.01\right)$. All pairwise comparisons that are not shown were highly significant $(* * *: p<0.001)$, e.g. panel a $5 \mathrm{~cm}$ vs $10 \mathrm{~cm}$

Prosthecochloris and Chlorobaculum (Fig. 6a, b, Additional file 1: Figure S10). In addition to phototrophs the bloom layers were enriched with sulfur-reducing Desulfuromonas $s p$. as well as Exiguobacterium sp. (Fig. 6a, Additional file 1: Figure S11). The layer above the bloom was slightly enriched with sulfur-oxidizing Thiovirga $s p$. and the layer below the bloom with Erypsipelothrix sp. Sulfate-reducing
Desulfobacteraceae and Desulfobulbaceae were observed at low relative abundances in all layers (Additional file 1: Figure S9B).

Interestingly, almost all Prosthecochloris affiliated reads belonged to a single sequence variant, while ASV diversity affiliated with the closely related Chlorobaculum increased over time (Fig. 6b, Additional file 1: 


\section{O $5 \lambda$}

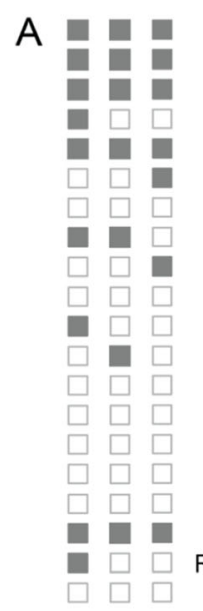

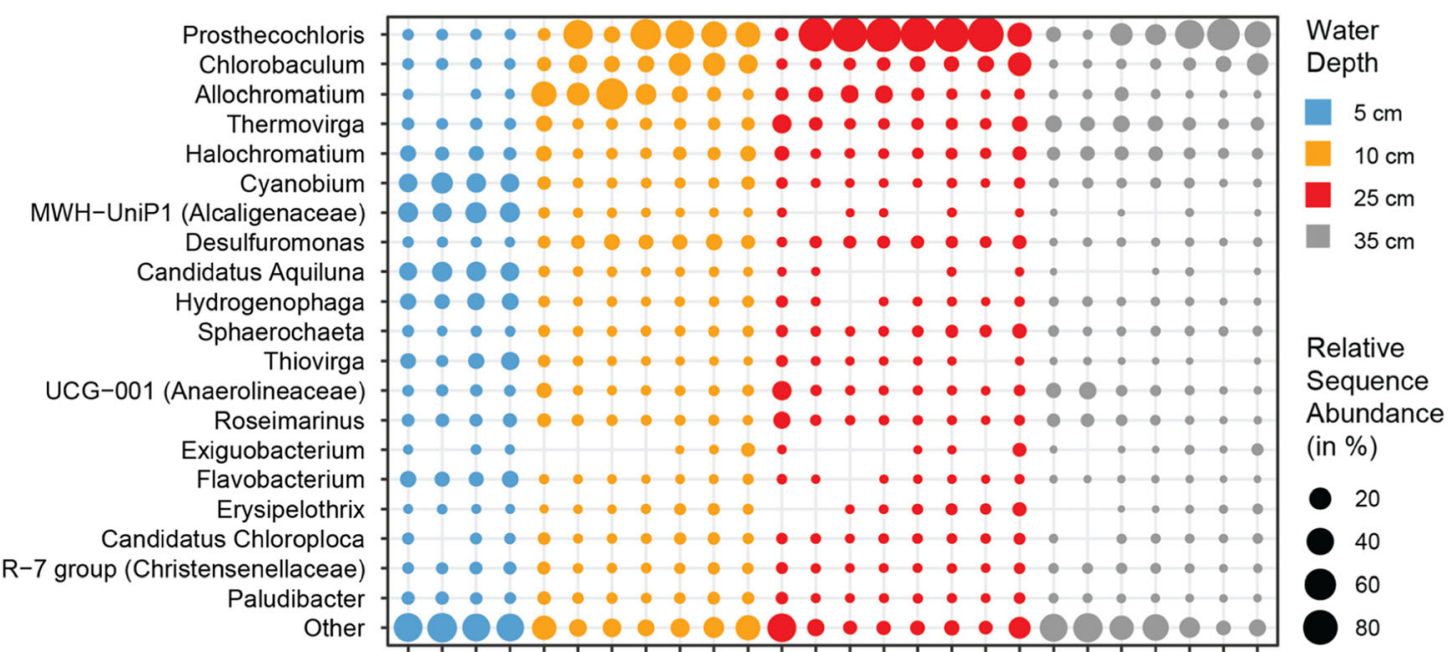

B

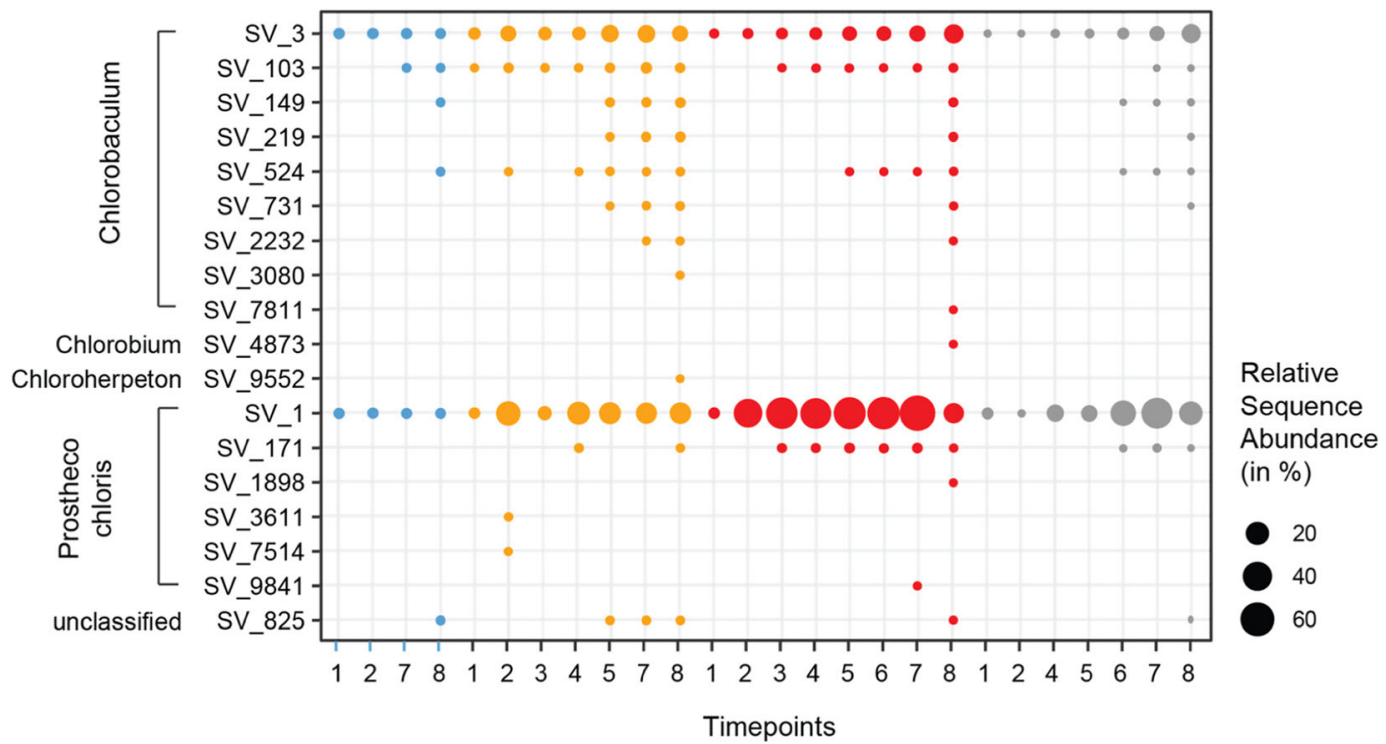

Fig. 6 Bacterial community composition on genus level. a Relative sequence abundance of genera found in different depth layers (colors) and timepoints (x-axis). Relative sequence abundances were averaged across triplicates, due to the high similarity of all three experiments. Clades that are anaerobic $(O)$, involved in the sulfur cycle $(S)$, or phototrophic $(\lambda)$ are indicated by full squares. b Relative sequence abundance of amplicon sequence variants (ASVs) within the order Chlorobiales. The graph shows average values of the three replicate experiments for clarity. The replicate experiments were very similar (see SI Additional file 1: Figure S9 and S10)

Figure S10). The relative sequence abundance of Chlorobiales was highest at $25 \mathrm{~cm}$ depth, coinciding with the microbial bloom layer that was richest in biomass (Fig. 2) and had the highest cell numbers (Additional file 1: Figure S4). Chlorobiales ASVs accounted for $>25 \%$ of reads in our dataset. To identify the phylogeny of ASV affiliating with Chlorobiales, we placed the representative sequence of each ASV on a reference tree of known Chlorobiales. The most abundant Chlorobiales ASV (ASV_1) affiliated with the genus Prosthecochloris, specifically with the monophyletic clade of Prosthecochloris vibrioformis (Additional file 1: Figure S12), followed by an ASV (ASV_2) affiliating with Chlorobaculum. Together, these two ASVs account for $>97 \%$ of the Chlorobiales reads. In general, we found a high number of unclassified lineages. The 20 most abundant ASVs accounted for about $50 \%$ of all sequences, twelve of those belonged to unclassified genera or families (Additional file 1: Figure S9B). The novelty was especially high within the Chromatiaceae where five ASVs, that ranked among the "top 20", belonged to an unclassified genus. 


\section{Metagenomics-derived insights into Chlorobiales populations}

We calculated the index of replication (iRep) [42] of the Prosthecochloris and Chlorobaculum populations based on the metagenome-assembled genomes (MAGs) that were recovered from the community metagenomes of two replicate experiments (Replicates A, E) and the enrichment culture (SK) at timepoint 7. Both populations were replicating rapidly. Prosthecochloris (bin10) had an iRep value of $3.7\left(r^{2}=0.90\right.$, sample 7A3), which indicates that on average every cell had 2.5 replication events at the time of sampling. Chlorobaculum (bin 6) had iRep values of $2.5\left(\mathrm{r}^{2}=0.95\right.$, sample $\left.7 \mathrm{E} 3\right)$ and $2.8\left(\mathrm{r}^{2}=0.95\right.$, sample $7 \mathrm{~K} 3$ ), indicating that on average every cell had 1.5 replication events. Both MAGs contained genes involved in oxidative sulfur metabolism including Dsr, SoxYZ (Additional file 1: Figure S17), Sqr and Fcc. Bin 6 also contained SoxXAB while Bin 10 contained PhsA. Components of assimilatory sulfate reduction (CysND and Cys) were also found in both MAGs. Genes for bacteriochlorophyll biosynthesis (BchEMU) were found in both MAGs. Bd-type oxidases (CydAB) were present in both MAGs, while heme-copper oxygen reductases were only found in Bin 6 including several cytochrome c oxidases (COX10, CyoABCDE and III) (Additional file 1: Table S4).

Bin 6 (Chlorobaculum sp.) and bin 10 (Prosthecochloris $s p$.) contained CRISPR arrays denoted as either type I (cas3) or III (cas10) CRISPR systems [43] (Additional file 1: Figure S18, S19). CRISPR predictions revealed three direct repeat sequences in both MAGs of 30, 35 and 35 bp in length for Bin 6 and 37, 32, and 33 for the Bin 10 (Additional file 1: Table S5). None of the spacers were shared by the closest reference and representative genomes or matched sequences in the CRISPR database [44]. However, a highly similar CRISPR array and direct repeat sequence were found between Bin 6 and Chlorobaculum parvum NCBI8327 with $60 \%$ cas genes similarity (Additional file 1: Figure S18). The metagenomes of all experiments, as well as of the GSB enrichment culture contained high relative sequence abundances of viruses affiliating with Myoviridae (Additional file 1: Figure S20).

\section{Discussion}

In this study, we created depressions in the organic matter layer of Trunk River to mimick disturbances of the layer that naturally occur at this site. We performed triplicate experiments that resulted in very similar physicochemical gradients and patterns of community structure enabling us to reliably study microbial community succession in a natural setting. The observed slight variations between replicate sites were likely due to small differences in the organic matter composition and distance to the lagoon inflow, or caused by weather, animals, and sampling. Disturbing the organic matter layer at our experimental sites (A-, E-, and K-hole) released trapped sulfide and caused the rapid establishment of steep physicochemical gradients as well as the development of a bloom of sulfide-oxidizing phototrophs. We monitored the microbial community assembly and succession, highlight the ecological niches of key populations and indicate syntrophic interactions between phototrophs and sulfur reducers.

\section{Sulfur cycling in the phototrophic bloom}

Sulfate concentrations in the bottom layers decreased substantially within the first days and were lowest in the bloom layer at $25 \mathrm{~cm}$ depth, where sulfate was almost entirely depleted. We found sulfate-reducers affiliating with Desulfobacteraceae and Desulfobulbaceae in the hypoxic layers of the bloom (Additional file 1: Figure S9B) likely producing sulfide using either hydrogen or organic acids, e.g. acetate (Additional file 1: Figure S6) released from fermented organic matter. The sulfide concentrations were highest at the upper boundary of the bloom at $10 \mathrm{~cm}$ water depth after the system stabilized around day six (Fig. 2). This is unexpected since reduced sulfur species, especially hydrogen sulfide, are the electron donor for the green and purple phototrophs and thus should have been depleted in these layers. At the same time, we found an increased relative abundance of sulfur-reducing Desulfuromonas sp. in the bloom layers, peaking at around $15 \%$ relative sequence abundance. Desulfuromonas $s p$. are known to live in freshwater ecosystems and reduce elemental sulfur to sulfide [45-47], which in turn can be reused by the sulfide-oxidizing phototrophs. Our findings suggest that the initially present sulfide was released from the sediment but was likely replenished by sulfate reducers from sulfate, as well as by sulfur reducers from sulfur. Sulfide (and thiosulfate) are oxidized to elemental sulfur by the anoxygenic phototrophs and hence the potential sulfur reduction by Desulfuromonas $s p$. indicates a syntrophic short sulfur cycle carried out by these organisms (Fig. 7). A similar synergistic interaction was suggested to occur in Lake Cadagno between sulfur disproportionating Desulfocapsa thiozymogenes and purple sulfur bacteria affiliating with Lamprocystis [48]. At early timepoints the microbial suspension was beige and opaque, indicating the presence of large amounts of elemental sulfur in the sample (Additional file 1: Figure S2). Later the samples turned yellow, likely due to an increase in phototrophic organisms and their photopigments (Figs. 2, 3 and 6), but also the suspension became translucent again (Additional file 1: Figure S2). This suggests that after a few days Desulfuromonas sp. reduced the elemental sulfur (possibly present as polysulfides) that was produced by the anoxygenic phototrophs and initially accumulated in the suspension. An observation that merits future research. Such a syntrophic sulfur cycle 


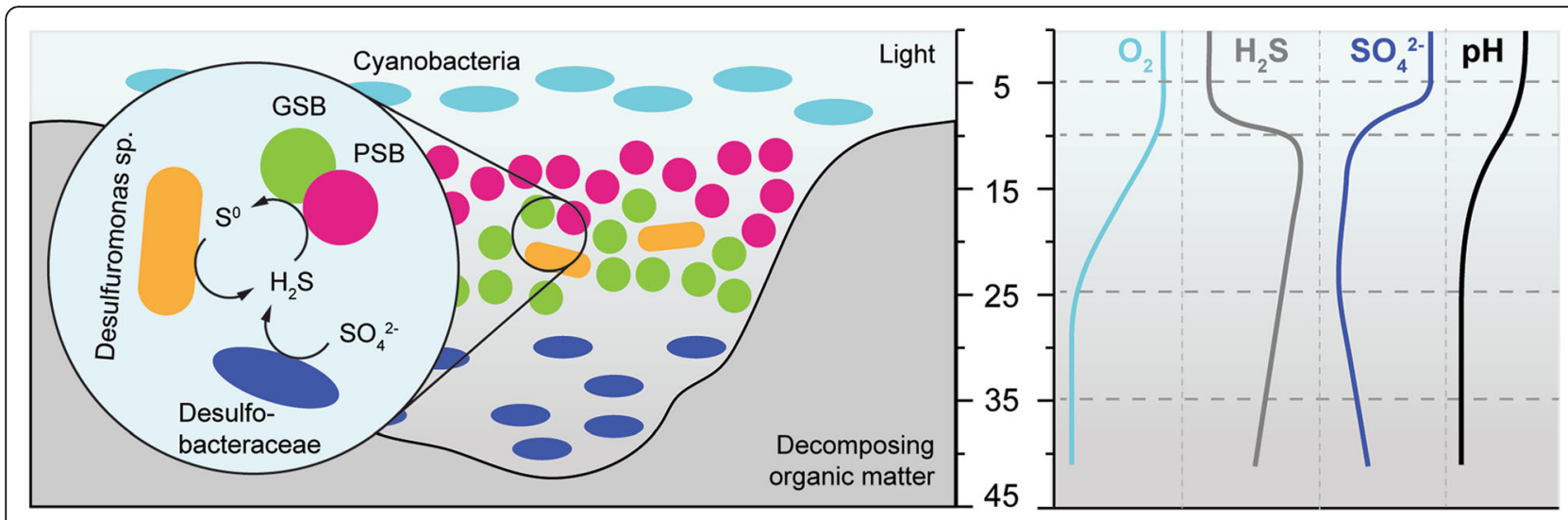

Fig. 7 Schematic overview of the phototrophic bloom showing relevant sulfur-cycling and phototrophic populations, sulfur compounds, and chemical gradients, as well as potential syntrophic interactions between green sulfur bacteria (GSB), purple sulfur bacteria (PSB) and Deltaproteobacteria. Depth is given in $\mathrm{cm}$

represents a positive feedback that could explain the abundance of sulfide in the bloom as well as the very rapid growth of the sulfur-oxidizing phototrophs. The involved phototophs and Deltaproteobacteria could even form tight aggregates similar to Chlorochromatium aggregatum [49], to efficiently use the sulfur intermediate.

\section{Assembly and coexistence of phototrophic microorganisms}

The multispecies phototrophic bloom (fondly termed "microbial lemonade", Fig. 1c) formed around two to four days post-disturbance and was fully established by day six. The bloom contained lineages from multiple phyla but was dominated by green and purple sulfur bacteria. The color of the bloom slightly shifted from beige at early timepoints to yellow-orange at mid timepoints to yellow-green at late timepoints (Additional file 1: Figure S2), likely due to the relative influence of the photopigments of green and purple sulfur bacteria. The change in bacteriochlorophylls is reflected by the pigment spectra collected at the different timepoints (Fig. 3). The opacity and color of the suspension, especially at the beginning of the experiment, is likely influenced by the presence of polysulfides that are produced abiotically [50], as well as biotically by purple and green sulfur bacteria due to their lack of soxCD genes [51].

Interestingly, the sequencing data suggest that especially the lower layer of the bloom was dominated by an apparently clonal population of green sulfur bacteria affiliated with Prosthecochloris vibrioformis. The green sulfur bacteria are sulfur-oxidizing, strictly anaerobic, obligate photoautotrophs [52]. Yet, based on oxygen measurements, the Trunk River GSB populations tolerated relatively high oxygen concentrations of around $30 \mu \mathrm{M}$, but up to $80 \mu \mathrm{M}$ (Fig. 2). The low concentration of dissolved oxygen at 25 $\mathrm{cm}$ depth combined with sulfide, salinity, and low light created an optimal habitat for Prosthecochloris sp. The observed community turnover (Fig. 5) indicates that communities in the layers 2-4 shifted from one stable state at the beginning of the experiment (timepoint 1) to an alternative stable state at the end of the experiment (timepoint 8). It appears that PSB (Allochromatium sp.) played a key role in stable state one, while the community of stable state two was equally dominated by both GSB populations (Prosthecochloris sp. and Chlorobium sp.). The change of relative abundances of phototrophs over the course of the experiment seems to be responsible for the pronounced community turnover, because together these few clades made up the majority of sequence reads. Chlorobiales have a high tolerance towards sulfide, and a higher affinity for sulfide than Chromatiales [53]. Together with their metabolic potential to cope with oxygen and their efficient growth at low light conditions [54] these capabilities may have enabled GSB to outcompete PSBs at the end of the experiment leading to a community adapted to the changed conditions.

Despite the dominance of few populations the disturbance created a habitat with gradients of $\mathrm{pH}$, salinity, light, oxygen, and sulfide that enabled the coexistence of multiple phototrophic clades from at least five different phyla (Actinobacteria, Chlorobi, Chloroflexi, Cyanobacteria and Gammaproteobacteria). Coexistence of multiple phototrophic lineages was observed before, especially in lakes $[21,55,56]$. The coexistence of organisms competing for the same energy source is due to the different absorption maxima of each clades' photopigments (Fig. 3), as well as their need for different electron donors, and the varying salinity and oxygen tolerances of each clade. At Trunk River $P$. vibrioformis relatives were absent at $5 \mathrm{~cm}$ and present only in low abundance at $10 \mathrm{~cm}$. The surface layer ( $5 \mathrm{~cm}$ depth) was inhabited by oxygenic phototrophic Cyanobacteria affiliating with Cyanobium, while the upper 
layer of the bloom $(10 \mathrm{~cm}$ depth) was dominated by purple sulfur bacteria of the order Chromatiales (Fig. 6). Because Prosthecochloris are adapted to low light conditions [57] and respond to different wavelengths of light than Cyanobacteria and photosynthetic Proteobacteria [58, 59], they thrived at depths of $25 \mathrm{~cm}$, where they out-competed other phototrophs. Prosthecochloris have been previously observed in many marine and saline habitats, such as the Black Sea [60], Baltic Sea, Sippewissett Salt Marsh, and Badwater basin [52]. They are considered to belong to a specialized phylogenetic lineage of green sulfur bacteria adapted for marine and salt water ecosystems. Blooms of $P$. vibrioformis have been previously observed in stratified lakes, where they dominate the community at a specific depth [61], sometimes forming clonal blooms [62].

The phototrophs in the pelagic bloom were layered analogous to the phototrophs in benthic mats in the nearby Sippewissett Salt Marsh [63-65] and elsewhere $[66,67]$. The disturbance experiment apparently created transient pelagic ecosystems with niches resembling those in benthic phototrophic mats. The bloom slowly collapsed after about two weeks and the water column seemed to return to almost its original state (Fig. 4). We did not observe a shift from phototrophic to chemotrophic sulfur oxidation after the phototrophic bloom [21].

\section{New species of green sulfur bacteria and possible viral predation}

In a previous study based on $16 \mathrm{~S}$ rRNA gene libraries, Imhoff and colleagues proposed the existence of several uncultivated GSB species in Sippewissett Salt Marsh and other estuaries [52]. The authors provide evidence that several GSB clades harbor species that have defied isolation, among those are species in the genera Chlorobaculum and Prosthecochloris. We have strong evidence that we found at least two of these uncultured species based on MAGs of a Chlorobaculum species (Bin 6, Additional file 1: Figure S13, S15) and a Prosthecochloris species (Bin 10, Additional file 1: Figure S13, S16). Both MAGs cluster sufficiently far away from the closest cultured isolate (Additional file 1: Figure S12, S14) and have average nucleotide identity (ANI) values of $<90$ to their respective closest cultured isolate.

The MAGs of the phototrophic populations represented by bin 6 and 10 encoded for enzymes performing sulfide and thiosulfate oxidation. All known GSB contain the sulfide:quinone oxidoreductase (SQR) and the dissimilatory sulfite reductase (DSR) system (the latter is missing only in Chloroherpeton thalassium) that oxidize sulfide to sulfite [68]. Bin 6 and 10 featured the SQR and DSR systems as well. Additionally, bin 10 contained PhsA encoding for a thiosulfate reductase that may further oxidize sulfite to thiosulfate [69]. As in most GSB, bin 6 contained the genes SoxABXYZ coding for enzymes that oxidize thiosulfate to sulfate and polysulfides [70]. Bin 10 only contained SoxYZ (Additional file 1: Figure S17). The absence of SoxB genes has been identified in other non-thiosulfate oxidizing GSB such as the close relative Prosthecochloris estuarii, or in Chlorobium limicola DSM 245 and Chlorobium luteolum DSM 273 [71]. Both MAGs also contained the flavocytochrome c (FccB) involved in oxidative sulfur metabolism [68]. Bacteriochlorophyll synthesis genes were identical in both MAGs coding for pigments common to Chlorobi. In bin 6 we found complete operons encoding for cytochrome o oxidase (CyoABCDE) and cytochrome d oxidase (CydAB) [72]. The latter was found also in bin 10, indicating that both organisms have means to cope with oxygen stress. The presence of GSB at relatively high oxygen concentrations in Trunk River and their ability to perform anoxygenic photosynthesis at hypoxic conditions contrasts the general assumption that GSB are strict anaerobes in situ and in vitro [53, 73]. Heme-copper oxygen reductases similar to the ones we found in the Chlorobi MAGs have been found in other Chlorobi genomes including Chlorobaculum parvum (COX10, CyoABCDE, I, II, and III) and Chlorobaculum limnaeum (I, II, and III).

Both MAGs also contain CRISPR-Cas systems that are different from the closest cultured isolates (Additional file 1: Figure S18, S19). Our CRISPR results indicate that Trunk River populations are under viral predatory stress, affecting the abundance of bacterial blooms, and that host immunity is active in this ecosystem [74]. The unique CRISPR arrays indicate that closely related species may be infected by different viruses with species specificity [75]. However, some viral populations have been reported to have broad host ranges [76]. Divergent evolution or strain level microdiversity may also explain distinct CRISPR-Cas systems [77]. A lack of public databases containing viral sequences restricts the detection of viral-host interactions [78]. While Llorens-Marès et al. (2017) characterized a potential green sulfur bacteria viral infection, to date, phages infecting Chlorobi have not been reported. Our analyses suggest that viruses of the family Myoviridae played a role in the transient bloom (Additional file 1: Figure S20), and were possibly responsible for the blooms demise.

\section{Conclusions}

In this study, we investigated phototrophic blooms that naturally occur in a brackish estuarine ecosystem to understand the underlying microbial and biogeochemical dynamics. Photosynthetically active radiation, the degree of anaerobiosis and nutrient supply are the main selecting factors in this stratified water body. The release of sulfide by heterotrophs and heterotrophic 
sulfate-reducers creates a habitat selecting for anoxygenic phototrophs, provided that enough light reaches the euxinic zone. The necessary light penetration occurs by disturbing or removing the dense covers of decaying seagrass, creating niches for phototrophic primary producers, sulfur oxidizers, as well as sulfur and sulfate reducers. We show that phototrophs belonging to five bacterial phyla spatially organized within the water column based on their light requirements and oxygen tolerance, forming a layered bloom, analogous to the layered communities in phototrophic microbial mats (Fig. 7). Our findings suggest the presence of a syntrophic sulfur cycle between anoxygenic phototrophs and sulfur reducers that could explain the rapid development of the bloom. We identified metagenome assembled genomes of two novel species of green sulfur bacteria, belonging to Chlorobaculum and Prosthecochloris. Contigs of viral sequences in the metagenomes suggest that Myoviridae viruses infect species within the Chlorobiales. This finding indicates a high degree of host-virus dynamics and a potential key regulating factor for the control of phototrophic blooms. In addition to genes coding for the multi-enzyme Sox complex, sulfide-quinone oxidoreductases, dissimilatory sulfite reductase and photopigment biosynthesis, the Chlorobiales MAGs also contained complete operons encoding for terminal oxidases, heme-copper oxygen reductases and cytochrome $\mathrm{c}$ and $\mathrm{d}$ oxidases. The activity of these oxidases may allow the organisms to thrive in the presence of oxygen. Future research addressing oxidase activity will tell whether Chlorobiales are as strictly anaerobic as is generally assumed. We consider the Trunk River lagoon an excellent model ecosystem to study the microbial community dynamics, syntrophy and ecophysiology in phototrophic bloom microbiomes in a natural setting.

\section{Methods}

\section{Experimental setup and sample collection}

We used custom-made sampling poles for long-term environmental monitoring of the water column without disturbing the established gradients (Fig. 1b, c). The sampling poles were placed in three replicate depressions (A-hole, E-hole, and K-hole) that we dug into the thick layers of decaying organic matter (Fig. 1a). In each of the sites, a sampling pole was placed such that the inlets sampled water at $5 \mathrm{~cm}, 10 \mathrm{~cm}, 25 \mathrm{~cm}$, and $35 \mathrm{~cm}$ depth below the water surface (Fig. 1b, c). Sampling poles were set up 1 day after the holes were created and sampling began 1 day after set up ( 2 days post disturbance), to allow disturbed sediment to settle. Samples were collected over a 15-day period during July-August 2015. For each sample, the first $50 \mathrm{ml}$ were discarded, followed by collection of $100 \mathrm{ml}$ of water in sterile tubes for further analyses. The tubes were transported on ice to the laboratory and stored at $4{ }^{\circ} \mathrm{C}$. All sample collections were carried out between $4 \mathrm{pm}$ and $6 \mathrm{pm}$.

\section{Enrichment culture}

To enrich for GSB we used a defined saltwater medium ( $400 \mathrm{~g} / \mathrm{l} \mathrm{NaCl}, 60 \mathrm{~g} / \mathrm{l} \mathrm{MgCl}_{2}{ }^{*} 6 \mathrm{H}_{2} \mathrm{O}, 3 \mathrm{~g} / \mathrm{l} \mathrm{CaCl}{ }_{2}{ }^{*} 2 \mathrm{H}_{2} \mathrm{O}, 10$ $\mathrm{g} / \mathrm{l} \mathrm{KCl}$ ) buffered at $\mathrm{pH} 7.2$ with $5 \mathrm{mM}$ MOPS. The medium contained $5 \mathrm{mM} \mathrm{NH}_{4} \mathrm{Cl}$ as $\mathrm{N}$ source, $1 \mathrm{mMK}$ phosphate (pH 7.2) as $\mathrm{P}$ source, $70 \mathrm{mM} \mathrm{NaHCO}$ as $\mathrm{C}$ source, $10 \mathrm{mM} \mathrm{Na} \mathrm{S}_{2} \mathrm{O}_{3}$ as electron donor, $1 \mathrm{mM} \mathrm{Na}_{2} \mathrm{~S}$ as reductant or electron donor, a multivitamin solution prepared at $1000 \times$ in $10 \mathrm{mM}$ MOPS at $\mathrm{pH} 7.2$, and a trace metal solution prepared at $1000 \times$ in $20 \mathrm{mM} \mathrm{HCl}$. Saltwater base, MOPS, N- and P-source, and trace metals were autoclaved together in a Widdel sparging flask, cooled under a stream of $\mathrm{N}_{2} / \mathrm{CO}_{2}(80 \%: 20 \%)$ gas. $\mathrm{C}$-source, electron donors and vitamins were added from filter-sterilized stock solutions after cooling. The medium was inoculated with biomass removed from in situ enrichments of GSB grown on glass slides using a $770 \mathrm{~nm}$ monochromatic LED. After inoculation, the bottle was kept in dark for $2-4 \mathrm{~h}$ and then placed $5 \mathrm{~cm}$ away from a LED light source with the same specifications. After visible sign of growth - green coloration the culture was filtered through $0.2 \mu \mathrm{m}$ filter and used for DNA extraction, similar to other samples.

\section{Physicochemical measurements}

In-situ measurements of $\mathrm{pH}$, temperature, dissolved oxygen, oxidation reduction potential (ORP), and ion selective electrode (ISE) measurements were carried out with a multi-parameter probe equipped with a quarto probe (YSI Professional Series Model Pro). The probe was calibrated for $\mathrm{pH}$ with $\mathrm{pH} \mathrm{4,} \mathrm{7,} \mathrm{and} 10$ buffers and for dissolved oxygen using oxygen-saturated water and an anoxic solution of sodium ascorbate and sodium hydroxide. After each sample collection the probe was lowered into the water to each depth per site and after probe readings stabilized, the parameters were recorded.

To measure biomass and pigment spectra, up to $10 \mathrm{ml}$ of the collected sample were filtered through a sterile Millipore filter $(0.2 \mu \mathrm{m}$ GTTP, $0.2 \mu \mathrm{m}$ GNWP, or $0.22 \mu \mathrm{m} \mathrm{GV)}$. Filters were washed twice with ammonium acetate solutions with the same ionic strength as each depth. The filters were placed on aluminium foil, dried at $60^{\circ} \mathrm{C}$ overnight and subsequently weighed (Additional file 1: Figure S3). A Spectral Evolution SR1900 spectrophotometer was used to measure the spectrum of the dried biomass on each filter with a scanning range of $350-1900 \mathrm{~nm}$. The light source was a Dyonics $60 \mathrm{~W}$ lamp. 
After sterile filtration, the filtrate was used to measure anion, cation, and organic acid concentrations using an ion chromatographer. The ion concentrations of samples were measured by diluting filtrate 1:10 with Millipore water to a total volume of $2 \mathrm{ml}$. The diluted samples were measured in triplicate using a ThermoFisher/Dionex ICS2100 equipped with an AS18 column using a 13 min, $33 \mathrm{mM} \mathrm{NaOH}$ isocratic program to measure anions and a CS12A column using a $13 \mathrm{~min}, 25 \mathrm{mM}$ methane sulfonic acid isocratic program to measure cations. Samples for organic acid analysis were filtered through $0.2 \mu \mathrm{m}$ filters and $900 \mu \mathrm{L}$ of filtrate was added to $100 \mu \mathrm{L}$ of $5 \mathrm{M} \mathrm{H}_{2} \mathrm{SO}_{4}$ to precipitate any compounds that might otherwise do so on the column. The samples were centrifuged and the upper portion was removed for HPLC analysis. Samples were analyzed on a BioRad Aminex HPX-87H column in isocratic elution mode with $5 \mathrm{mM}$ sulfuric acid.

Iron concentration was quantified using the ferrozine assay [79]. $4.5 \mathrm{ml}$ filtrate were added on site to $0.5 \mathrm{ml}$ of $1 \mathrm{M} \mathrm{HCl}$ to prevent oxidation of any available $\mathrm{Fe}(\mathrm{III})$. For Fe(II), $50 \mu \mathrm{l}$ filtrate was added to $50 \mu \mathrm{l}$ of $1 \mathrm{M} \mathrm{HCl}$ and $100 \mu \mathrm{l}$ of ferrozine $(0.1 \%$ [wt $/ \mathrm{vol}]$ in $50 \%$ ammonium acetate) was added. For total iron, $50 \mu \mathrm{l}$ filtrate was added to $50 \mu \mathrm{l}$ of $10 \%$ hydroxylamine hydrochloride in $1 \mathrm{M} \mathrm{HCl}$ to reduce $\mathrm{Fe}(\mathrm{III})$ to $\mathrm{Fe}(\mathrm{II})$. Samples were added to $100 \mu \mathrm{l}$ of ferrozine. All samples were incubated for 15 min and filtrate absorbances were read in triplicate at $560 \mathrm{~nm}$ using a Promega plate reader. Ferrous ammonium sulfate was used as standard.

Sulfide concentrations were quantified using the Cline assay [80]. $1.5 \mathrm{ml}$ filtrate were added on site to $500 \mu \mathrm{l}$ of zinc acetate solution $(91 \mathrm{mM})$ to prevent oxidation of the sulfide. Cline reagent ( $\mathrm{N}, \mathrm{N}$-dimethyl-p-phenylenediamine sulfate, $\left.\mathrm{H}_{2} \mathrm{SO}_{4}, \mathrm{NH}_{4} \mathrm{Fe}\left(\mathrm{SO}_{4}\right)_{2} \cdot 12 \quad \mathrm{H}_{2} \mathrm{O}\right)$ was added, the samples were incubated in the dark for 30 min and absorbance was read at $665 \mathrm{~nm}$. A table with all physicochemical and biomass measurements is publicly available at PANGAEA (https://doi.pangaea.de/1 0.1594/PANGAEA.900343).

\section{DNA extraction, library preparations, and sequencing}

Within 2-6 h of sample collection, $50 \mathrm{ml}$ sample was filtered using an autoclaved $0.2 \mu \mathrm{m}$ polycarbonate filter (GTTP Millipore) and stored at $-20^{\circ} \mathrm{C}$. Each filter was cut with a sterile blade and extracted with the MoBio PowerFecal kit. We followed the protocol, but instead of bead beating, the samples were twice vortexed horizontally with the beads (10 min and $20 \mathrm{~min}$ with a $10 \mathrm{~min}$ pause). DNA concentration and purity were measured with Promega Qubit fluorometer and Nanodrop, respectively.

We prepared 16S rRNA gene amplicon libraries using V4-V5 fusion primers as previously described [81]. Briefly, the fusion primer contains TruSeq adapter sequences, barcodes, and the forward or reverse $16 \mathrm{~S}$ rRNA gene primers. The forward and reverse 16S rRNA gene primers were 518F (CCAGCAGCYGCGGTAAN) and 926R (CCGTCAATTCNTTTRAGT). The PCR conditions were as follows: initial denaturation of $94{ }^{\circ} \mathrm{C}$ for 3 min, 30 cycles of denaturation at $94{ }^{\circ} \mathrm{C}$ for $30 \mathrm{~s}$, annealing at $57^{\circ} \mathrm{C}$ for 45 s, extension at $72{ }^{\circ} \mathrm{C}$ for $1 \mathrm{~min}$, and final extension at $72{ }^{\circ} \mathrm{C}$ for $2 \mathrm{~min}$. The libraries were cleaned using Agencourt Ampure XP beads, quantified using picogreen, pooled in equimolar ratios, and cleaned again using Agencourt Ampure XP beads a second time. The indexed libraries were then sequenced on the Illumina MiSeq PE250 platform.

DNA from $25 \mathrm{~cm}$ depth at timepoint 7 from each of the three replicate sites, as well as from a phototrophic enrichment culture were used to generate whole-genome shotgun metagenomic library. The DNA was sheared using Covaris sonicator, size selected for 500-600 bp using Pippin prep, and cleaned using Agencourt Ampure XP clean beads. The cleaned DNA was analyzed using Bioanalyzer DNA1000 chip and used to prepare metagenomic library using Nugen Ovation ultralow DR multiplex kit with manufacture supplied protocol. The libraries were then sequenced on Illumina MiSeq PE250 platform. All the sequencing was performed at the Keck facility at J. Bay Paul Center, Marine Biological Laboratory, Woods Hole, MA.

\section{Amplicon sequence data analyses}

The amplicon data was demultiplexed in mothur v1.39.5 [82], followed by the trimming of $16 \mathrm{~S}$ rRNA gene amplification primers using Cutadapt v1.16 [83] with default parameters. The primer-trimmed amplicon sequencing data was quality checked using DADA2 v1.9.0 $\mathrm{R}$ Package [84]. In DADA2, the reads were trimmed at the first instance of quality drop below 8 , an expected error rate of 2, followed by trimming to $220 \mathrm{bp}$ and $200 \mathrm{bp}$ for forward and reverse reads. Any reads that matched PhiX or had an ambiguous base were removed. An error profile for the forward and reverse reads was generated using learnErrors function and then used to merge the forward and reverse reads using the mergePairs function. The merged reads were used to generate the amplicon sequence variants using makeSequenceTable function, which was then filtered for chimeras using removeBimeraDenovo function. The amplicon sequence variants were assigned taxonomy in DADA2 using Silva reference database v132 [85]. Community analyses were performed using a custom workflow based on $\mathrm{R}$ and the packages vegan, labdsv, tidyverse (stringr, dplyr, ggplot2), UpSetR and custom scripts [86-91]. Relative abundance of bacterial ASVs (amplicon sequence variants), Bray-Curtis dissimilarities, Nonmetric Multidimensional Scaling as well as analyses 
determining Singletons and percent shared ASVs are based on the unaltered SamplexASV table as calculated by DADA2. The ASV $\times$ Sample table including taxonomy is available at PANGAEA (https://doi.pangaea.de/10.1594/ PANGAEA.900354). To compare the diversity between samples using the number of observed species, Shannon index, Inverse Simpson diversity and Chao1 Richness [92] the ASV abundance tables were subsampled to account for unequal sampling effort using 31,682 randomly chosen sequences without replacement. For details refer to the $R$ workflow available at the public database PANGAEA (https://doi.pangaea.de/10.1594/PANGAEA.900344).

\section{Metagenomic sequence data analyses}

Quality control of the raw reads was performed using Preprocessing and Information of SEQuence data (PRINSEQ) to remove sequencing tags and sequences with mean quality score lower than 25, duplicates and ambiguous bases [93]. All runs combined provided a total of approximately 3.5 million $250 \mathrm{bp}$ read pairs. All forward and reverse reads were placed together in one file and cross coassembled with SPAdes using the --meta option [94]. Binning was performed using MetaBAT [95] and Anvi'o (v5.2) metagenomic workflow (CONCOCT) [96]. Completeness and contamination of bins was assessed using CheckM [97]. Assembled genomes that contained more than $90 \%$ genome completeness, less than $5 \%$ contamination, and sequences mainly from a single genus were further analyzed. This yielded two high quality bacterial metagenome-assembled genomes (MAGs): Bin 6 and Bin 10. Taxonomic composition for each bin was predicted using FOCUS [98]. Phylogenetic analysis including the identification of their closest phylogenetic neighbors was investigated using PATRIC Comprehensive Genome Analysis [99]. Gene prediction for MAGs was performed using prodigal (V2.60, - $\mathrm{p}$ meta). We searched for sulfur, terminal oxidases and chlorophyll pathways using GhostKOALA against the KEGG GENES database. The Chlorobi Bins 6 and 10 contained 2008 and 1938 predicted proteins, respectively. CRISPRCasFinder [100] and CRISPRone [101] were used to identify CRISPR repeat and spacer sequences. The quality checked reads from each sample were mapped to the MAGs, Bin 6 and Bin 10 using bowtie2 [102]. The mapped reads were then analyzed using iRep [42] to estimate replication events in Bin 6 and Bin 10. Unassembled sequences were processed on the MG-RAST platform version 4.0.3. Percent abundance of viral sequences was calculated from the RefSeq database using an e-value cutoff of 1e-5, a minimum identity cutoff of $60 \%$, and an alignment length minimum cutoff of 15 [103]. For details refer to the metagenome analyses workflow publicly accessible at HackMD (https://hackmd. io/tGZyCM9sSNmuorpHenQVNA).

\section{Additional file}

\begin{abstract}
Additional file 1: Supplementary Materials, Methods and Results. Figure S1. Natural blooms in Trunk River. Figure S2. Color and appearance of samples from all holes, depths, and timepoints. Figure S3. Filters that were used for biomass measurements and spectral analysis. Figure S4. Total cell count of three samples (A2, A7 and K7). Figure S5. Depth profile representation of chemical data presented in Fig. 2. Figure S6. Physicochemistry. Iron, nitrate, ammonium, acetate, $\mathrm{Ca}^{2+}$, and $\mathrm{K}^{+}$ measurements. Figure S7. Individual diversity indices of all samples. Figure S8. Trajectories of community structure in hole A, E and K. Figure S9. Relative sequence abundance of the 20 most abundant clades on phylum, class, order, family and genus level, as well as the 20 most sequence abundant ASVs (amplicon sequence variants). Figure S10. Relative sequence abundance of Chlorobiales ASVs. Figure S11. Relative change of ASV abundance between surface (V1) and deeper layers (V2-4). Figure S12. Chlorobiales phylogeny. Figure S13. Circular map of metagenome-assembled genomes (MAGs). Figure S14. Chlorobiales phylogenomics. Figure S15. Protein comparison of Bin 6. Figure S16. Protein comparison of Bin 10. Figure S17. Genes involved in sulfur cycling. Figure S18. CRISPR arrays and cas genes predictions Bin 6. Figure S19. CRISPR arrays and cas genes predictions Bin 10. Figure S20. Relative sequence abundance of viral family-level clades. Table S1. Overview of sequencing output and diversity indices. Table S2. Genome statistics. Table S3. Average nucleotide identity (ANI) comparisons. Table S4. Oxidative phosphorylation and chlorophyll biosynthesis genes of Bin 6 and Bin 10. Table S5. CRISPR-Cas system information for each metagenome-assembled genome.
\end{abstract}

\section{Acknowledgements}

We would like to express our deepest gratitude towards Dianne Newman and Jared R. Leadbetter, directors of the Microbial Diversity Summer Course 2014-2017 at the Marine Biological Laboratory. Without their trust, support and encouragement the project would not have been realized. We are very grateful to Joseph Vineis, Kim Finnegan, and Mitchell Sogin for providing laboratory space, equipment, and guidance regarding next-generation sequencing. We are also very grateful to the students and staff of the 2015 Microbial Diversity Summer Course, specifically Kurt Dahlstrom, Kristina Garcia, Jessica Choi, Moritz Buck, Rachel Soble, and Lina Bird. We would like to thank the Simons Foundation, NSF, DOE, and NASA for funding the Microbial Diversity Summer course, as well as Promega, Thermo Fisher Scientific, Spectral Evolution, and MBL's Marine Resources Center for providing reagents and equipment used in this work.

\section{Authors' contributions}

SB helped design the study, collected samples, prepared and analyzed sequencing data, wrote manuscript. ESC helped design the study, collected samples, prepared and analyzed physicochemical data, wrote manuscript. SHK helped design the study and enrichment cultures, analyzed physicochemical data and pigment spectra, wrote manuscript. SPC analyzed metagenomic data, wrote manuscript. SK obtained enrichment culture, wrote manuscript. SD helped design the study, wrote manuscript. KH collected samples, prepared and analyzed physicochemical data and pigment spectra, wrote manuscript. SER designed the study, analyzed and visualized sequencing and physicochemical data, wrote manuscript with input from all co-authors. All authors read and approved the final manuscript.

\section{Funding}

This work was carried out at the Microbial Diversity summer course at the Marine Biological Laboratory in Woods Hole, MA. The course was supported by grants from National Aeronautics and Space Administration, the US Department of Energy, the Simons Foundation, the Beckman Foundation, and the Agouron Institute. Additional funding for SER was provided by the Marine Biological Laboratory.

\section{Availability of data and materials}

The genomic datasets generated and analyzed during the current study are available on MG-RAST (Project Name: Trunk River, ID: 4837589.3 (sample SK), 
4837590.3 (sample 7 K3), 4837591.3 (sample 7E3), 4837592.3 (sample 7A3)) and the metagenome-assembled genomes workflow is available on HackMD (https://hackmd.io/tGZyCM9sSNmuorpHenQVNA). The raw 165 rRNA gene amplicon data, the shotgun metagenomic data, the 16S rRNA gene clonal sequences, and the metagenome assembled genomes presented in this work are publicly archived in NCBI under Bioproject PRJNA530984 (https://www.ncbi. nlm.nih.gov/bioproject/530984). The contextual physicochemical datasets generated and analyzed during the current study are publicly available at PANGAEA under: https://doi.org/10.1594/PANGAEA.900343

\section{Competing interests}

The authors declare that they have no competing interests.

\section{Author details}

${ }^{1}$ Department of Biological Sciences, University of Calgary, Calgary, AB, Canada. ${ }^{2}$ School of Medicine and Public Health, University of Wisconsin-Madison, Madison, WI, USA. ${ }^{3}$ Department of Geological Sciences, University of Colorado, Boulder, CO, USA. ${ }^{4}$ Ecosystems Center and J. Bay Paul Center for Comparative Molecular Biology and Evolution, Marine Biological Laboratory, Woods Hole, MA, USA. ${ }^{5}$ Department of Biological Engineering, Massachusetts Institute of Technology, Cambridge, MA, USA. ${ }^{6}$ Department of Microbiology and Molecular Genetics, University of California Davis, Davis, CA, USA. ${ }^{7}$ Department of Earth Sciences, ETH, Zürich, Switzerland.

Received: 21 May 2019 Accepted: 25 November 2019

\section{Published online: 17 January 2020}

\section{References}

1. McLusky DS, Elliott M. The estuarine ecosystem: ecology, threats and management: Oxford University Press on Demand; 2004. Available from: http://www.oxfordscholarship.com/view/10.1093/acprof:oso/9780198525080. 001.0001/acprof-9780198525080

2. Moore WS. The subterranean estuary: a reaction zone of ground water and sea water. Mar Chem. 1999;65:111-25 Available from: http://www. sciencedirect.com/science/article/pii/S0304420399000146.

3. Pant HK, Reddy KR. Phosphorus Sorption Characteristics of Estuarine Sediments under Different Redox Conditions. J Environ Qual. 2001;30:1474 [cited 2019 Feb 13]. American Society of Agronomy, Crop Science Society of America, Soil Science Society; Available from: https://www.agronomy.org/ publications/jeq/abstracts/30/4/1474.

4. Jay DA, Orton PM, Chisholm T, Wilson DJ, Fain AMV. Particle trapping in stratified estuaries: Application to observations. Estuaries Coast. 2007;30: 1106-25 [cited 2019 Feb 13]. Springer-Verlag; Available from: http://link. springer.com/10.1007/BF02841400.

5. Nelson JL, Zavaleta ES. Salt marsh as a coastal filter for the oceans: changes in function with experimental increases in nitrogen loading and sea-level rise. PLoS One. 2012;7:e38558 Available from: https://doi.org/10.1371/journal. pone.0038558

6. Barbier EB, Hacker SD, Kennedy C, Koch EW, Stier AC, Silliman BR. The value of estuarine and coastal ecosystem services. Ecol Monogr. 2011;81:169-93 John Wiley \& Sons, Ltd [cited 2019 Jul 11]; Available from: http://doi.wiley. com/10.1890/10-1510.1.

7. Waidner LA, Kirchman DL. Aerobic anoxygenic photosynthesis genes and operons in uncultured bacteria in the Delaware River. Environ Microbiol. 2005;7:1896-908

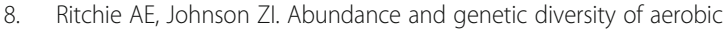
Anoxygenic phototrophic Bacteria of coastal regions of the Pacific Ocean. Appl Environ Microbiol. 2012;78:2858-66 Available from: http://aem.asm.org/ content/78/8/2858.abstract.

9. Boschker HTS, Vasquez-Cardenas D, Bolhuis H, Moerdijk-Poortvliet TWC, Moodley L. Chemoautotrophic carbon fixation rates and active bacterial communities in intertidal marine sediments. PLoS One. 2014;9:e101443 Available from: http://www.ncbi.n/m.nih.gov/pmc/articles/PMC4086895/.

10. Peduzzi P, Herndl GJ. Decomposition and significance of seagrass leaf litter (Cymodocea nodosa) for the microbial food web in coastal waters (gulf of Trieste, northern Adriatic Sea). Mar Ecol Prog Ser. 1991;71:163-74 Available from: http://www.jstor.org/stable/24817387.

11. Smith SV, Hollibaugh JT. Coastal metabolism and the oceanic organic carbon balance. Rev Geophys. 1993:31:75-89. Available from:. https://doi. org/10.1029/92RG02584.
12. Moran MA, Sheldon WM, Zepp RG. Carbon loss and optical property changes during long-term photochemical and biological degradation of estuarine dissolved organic matter. Limnol Oceanogr. 2000;45:1254-64. Available from:. https://doi.org/10.4319/lo.2000.45.6.1254.

13. Capone DG, Kiene RP. Comparison of microbial dynamics in marine and freshwater sediments: contrasts in anaerobic carbon catabolism. Limnol Oceanogr. 1988;33:725-49.

14. Purdy KJ, Embley TM, Nedwell DB. The distribution and activity of sulphate reducing bacteria in estuarine and coastal marine sediments. Antonie Van Leeuwenhoek. 2002;81:181-7. Available from. https://doi.org/10.1023/A: 1020550215012

15. Zopfi J, Ferdelman TG, Jørgensen BB, Teske A, Thamdrup B. Influence of water column dynamics on sulfide oxidation and other major biogeochemical processes in the chemocline of Mariager Fjord (Denmark) Mar Chem. 2001;74:29-51 Available from: http://www.sciencedirect.com/ science/article/pii/S0304420300000918.

16. Long RR. Mass and salt transfers and halocline depths in an estuary. Tellus. 1976;28:460-72. Available from:. https://doi.org/10.1111/j.2153-3490.1976. tb00695.x.

17. Lee DY, Owens MS, Doherty M, Eggleston EM, Hewson I, Crump BC, et al. The effects of oxygen transition on community respiration and potential chemoautotrophic production in a seasonally stratified anoxic estuary. Estuaries Coast. 2015;38:104-17 [cited 2019 Feb 13]. Springer US; Available from: http://link.springer.com/10.1007/s12237-014-9803-8.

18. Wimpenny JWT, Wiegel J, Kuenen JG. Responses of Microorganisms to Physical and Chemical Gradients [and Discussion]. Philos Trans R Soc Lond B Biol Sci. 1982;297:497-515 Available from: http://www.jstor.org/stable/2395933.

19. Jørgensen BB, Revsbech NP. Colorless sulfur bacteria, beggiatoa spp. and thiovulum spp., in $\mathrm{O} 2$ and $\mathrm{H} 2 \mathrm{~S}$ microgradients. Appl Environ Microbiol. 1983:45:1261-70 Available from: http://aem.asm.org/content/45/4/1261. abstract.

20. Møller MM, Nielsen LP, Jørgensen BB. Oxygen responses and mat formation by Beggiatoa spp. Appl Environ Microbiol. 1985;50:373-82 Available from: http://aem.asm.org/content/50/2/373.abstract.

21. Pjevac P, Korlević M, Berg JS, Bura-Nakić E, Ciglenečki I, Amann R, et al. Community shift from phototrophic to chemotrophic sulfide oxidation following anoxic holomixis in a stratified seawater lake. Appl Environ Microbiol. 2015;81:298-308 American Society for Microbiology; [cited 2019 Mar 28]. Available from: http://www.ncbi.nlm.nih.gov/pubmed/25344237.

22. Wasmund K, Mußmann M, Loy A. The life sulfuric: microbial ecology of sulfur cycling in marine sediments. Environ Microbiol Rep. 2017;9:323-44 John Wiley \& Sons, Ltd (10.1111); 2017 [cited 2019 Jul 23]. Available from: http://doi.wiley.com/10.1111/1758-2229.12538.

23. Bush T, Diao M, Allen RJ, Sinnige R, Muyzer G, Huisman J. Oxic-anoxic regime shifts mediated by feedbacks between biogeochemical processes and microbial community dynamics. Nat Commun. 2017;8:789 Nature Publishing Group; [cited 2019 Jul 23]. Available from: http://www.nature. com/articles/s41467-017-00912-x.

24. Zhu K, Lauro FM, Su H. Stratification modelling of key bacterial taxa driven by metabolic dynamics in meromictic lakes. Sci Rep. 2018;8:9538 Nature Publishing Group; [cited 2019 Jul 23];Available from: http://www.nature. com/articles/s41598-018-27973-2.

25. Haas LW. The effect of the spring-neap tidal cycle on the vertical salinity structure of the James, York and Rappahannock Rivers, Virginia, U.S.A. Estuar Coast Mar Sci. 1977;5:485-96 Available from: http://www.sciencedirect.com/ science/article/pii/0302352477900962.

26. Allen GP, Salomon JC, Bassoullet P, Du Penhoat Y, de Grandpré C. Effects of tides on mixing and suspended sediment transport in macrotidal estuaries. Sediment Geol. 1980;26:69-90 Elsevier; [cited 2019 Feb 13]. Available from: https://www.sciencedirect.com/science/article/pii/0037073880900068.

27. Garvine RW. A simple model of estuarine subtidal fluctuations forced by local and remote wind stress. J Geophys Res. 1985;90:11945-8 John Wiley \& Sons, Ltd; [cited 2019 Feb 13];Available from: http://doi.wiley.com/10.1029/ JC090iC06p11945.

28. Simpson JH, Brown J, Matthews J, Allen G. Tidal straining, density currents, and stirring in the control of estuarine stratification. Estuaries. 1990;13:12532. Available from. https://doi.org/10.2307/1351581.

29. Maie N, Boyer JN, Yang C, Jaffé R. Spatial, geomorphological, and seasonal variability of CDOM in estuaries of the Florida Coastal Everglades. Hydrobiologia. 2006;569:135-50. Available from. https://doi.org/10.1007/ s10750-006-0128-x. 
30. Badr E-SA, Tappin AD, Achterberg EP. Distributions and seasonal variability of dissolved organic nitrogen in two estuaries in SW England. Mar Chem. 2008;110:153-64 Available from: http://www.sciencedirect.com/science/ article/pii/S0304420308000686

31. Muylaert K, Sabbe K, Vyverman W. Spatial and temporal dynamics of phytoplankton communities in a freshwater tidal estuary (Schelde, Belgium). Estuar Coast Shelf Sci. 2000;50:673-87 Available from: http://www. sciencedirect.com/science/article/pii/S0272771400905900.

32. Bernhard AE, Colbert D, McManus J, Field KG. Microbial community dynamics based on 165 rRNA gene profiles in a Pacific Northwest estuary and its tributaries. FEMS Microbiol Ecol. 2005;52:115-28. Available from:. https://doi.org/10.1016/j.femsec.2004.10.016.

33. Henriques IS, Alves A, Tacão M, Almeida A, Cunha Â, Correia A. Seasonal and spatial variability of free-living bacterial community composition along an estuarine gradient (Ria de Aveiro, Portugal). Estuar Coast Shelf Sci. 2006; 68:139-48 Available from: http://www.sciencedirect.com/science/article/pii/ S0272771406000497.

34. Lv X, Ma B, Yu J, Chang SX, Xu J, Li Y, et al. Bacterial community structure and function shift along a successional series of tidal flats in the Yellow River Delta. Sci Rep. 2016;6:36550. Available from:. https://doi.org/10.1038/ srep36550.

35. Aguirre M, Abad D, Albaina A, Cralle L, Goñi-Urriza MS, Estonba A, et al. Unraveling the environmental and anthropogenic drivers of bacterial community changes in the Estuary of Bilbao and its tributaries. Kelly JJ, editor. PLoS One. 2017;12:e0178755. Public Library of Science; [cited 2019 Jul 12]Available from:. https://doi.org/10.1371/journal.pone.0178755.

36. Zaikova E, Walsh DA, Stilwell CP, Mohn WW, Tortell PD, Hallam SJ. Microbial community dynamics in a seasonally anoxic fjord: Saanich Inlet, British Columbia. Environ Microbiol. 2010;12:172-91 John Wiley \& Sons, Ltd (10. 1111)[cited 2019 Feb 13]. Available from: http://doi.wiley.com/10.1111/ j.1462-2920.2009.02058.x.

37. Oren A. Characterization of pigments of prokaryotes and their use in taxonomy and classification. Methods Microbiol. 2011;38:261-82 Academic Press; [cited 2019 Mar 26]. Available from: https://www.sciencedirect.com/ science/article/pii/B9780123877307000127.

38. Srinivas TNR, Anil Kumar P, Sucharitha K, Sasikala C, Ramana CV. Allochromatium phaeobacterium sp. nov. Int J Syst Evol Microbiol. 2009;59:750-3.

39. Caumette P, Imhoff JF, Süling J, Matheron R. Chromatium glycolicum sp. nov., a moderately halophilic purple sulfur bacterium that uses glycolate as substrate. Arch Microbiol. 1997:167:11-8.

40. Stomp M, van Dijk MA, van Overzee HMJ, Wortel MT, Sigon CAM, Egas M, et al. The timescale of phenotypic plasticity and its impact on competition in fluctuating environments. Am Nat. 2008;172:169-85 The University of Chicago Press; [cited 2019 Mar 26]Available from: https://www.journals. uchicago.edu/doi/10.1086/591680.

41. Borrego CM, Gerola PD, Miller M, Cox RP. Light intensity effects on pigment composition and organisation in the green sulfur bacterium Chlorobium tepidum. Photosynth Res. 1999;59:159-66 Kluwer Academic Publishers; [cited 2019 Mar 26]Available from: http://link.springer.com/10.1023/A:1 006161302838

42. Brown CT, Olm MR, Thomas BC, Banfield JF. Measurement of bacterial replication rates in microbial communities. Nat Biotechnol. 2016;34:1256-63 Nature Publishing Group; [cited 2018 Dec 18]. Available from: http://www. nature.com/articles/nbt.3704.

43. Makarova KS, Wolf YI, Alkhnbashi OS, Costa F, Shah SA, Saunders SJ, et al. An updated evolutionary classification of CRISPR-Cas systems. Nat Rev Microbiol. 2015;13:722-36 Nature Publishing Group.

44. Grissa I, Vergnaud G, Pourcel C. The CRISPRdb database and tools to display CRISPRs and to generate dictionaries of spacers and repeats. BMC Bioinformatics. 2007:8:1-10

45. Finster K, Bak F, Pfennig N. Desulfuromonas acetexigens sp. nov., a dissimilatory sulfur-reducing eubacterium from anoxic freshwater sediments. Arch Microbiol. 1994;161:328-32 Springer-Verlag; [cited 2019 Feb 8]. Available from: http://link.springer.com/10.1007/BF00303588.

46. Finster K, Coates JD, Liesack W, Pfennig N. Desulfuromonas thiophila sp. nov., a new Obligately sulfur-reducing bacterium from anoxic freshwater sediment. Int J Syst Bacteriol. 1997;47:754-8.

47. Pfennig $\mathrm{N}$, Biebl H. Desulfuromonas acetoxidans gen. nov. and sp. nov., a new anaerobic, sulfur-reducing, acetate-oxidizing bacterium. Arch Microbiol. 1976;110:3-12 Springer-Verlag; [cited 2019 Feb 8]. Available from: http://link. springer.com/10.1007/BF00416962.
48. Tonolla M, Peduzzi S, Demarta A, Peduzzi R, Hahn D. Phototropic sulfur and sulfate-reducing bacteria in the chemocline of meromictic Lake Cadagno, Switzerland. J Limnol. 2004;63:161 [cited 2019 Jul 9]. Available from: http:// jlimnol.it/index.php/jlimnol/article/view/jlimnol.2004.161.

49. Wanner G, Vogl K, Overmann J. Ultrastructural characterization of the prokaryotic symbiosis in \&quot;Chlorochromatium aggregatum\&quot. J Bacteriol. 2008;190:3721-30 American Society for Microbiology Journals; [cited 2019 Apr 8]. Available from: http://www.ncbi.nlm.nih.gov/pubmed/18344357.

50. Findlay AJ. Microbial impact on polysulfide dynamics in the environment. Boden R, editor. FEMS Microbiol Lett. 2016;363:fnw103 Narnia; [cited 2019 Jul 24]Available from: https://academic.oup.com/femsle/article-lookup/doi/1 0.1093/femsle/fnw103.

51. Welte C, Hafner S, Krätzer C, Quentmeier A, Friedrich CG, Dahl C. Interaction between Sox proteins of two physiologically distinct bacteria and a new protein involved in thiosulfate oxidation. FEBS Lett. 2009:583:1281-6 John Wiley \& Sons, Ltd. [cited 2019 Jul 8]Available from: http://doi.wiley.com/10.1 016/j.febslet.2009.03.020.

52. Alexander B, Imhoff JF. Communities of green sulfur bacteria in marine and saline habitats analyzed by gene sequences of 165 rRNA and FennaMatthews-Olson protein. Int Microbiol. 2006;9:259-66.

53. Van Gemerden H, Mas J. Ecology of phototrophic sulfur bacteria. Dordrecht: Springer; 1995. p. 49-85. [cited 2019 Oct 18]. Available from: http://link. springer.com/10.1007/0-306-47954-0_4

54. Veldhuis MJW, Gemerden H. Competition between purple and brown phototrophic bacteria in stratified lakes: sulfide, acetate, and light as limiting factors. FEMS Microbiol Lett. 1986:38:31-8 Narnia; [cited 2019 Jul 11]. Available from: https://academic.oup.com/femsec/article-lookup/doi/1 0.1111/j.1574-6968.1986.tb01936.x.

55. Tonolla M, Peduzzi R, Hahn D. Long-term population dynamics of phototrophic sulfur bacteria in the chemocline of Lake Cadagno, Switzerland. Appl Environ Microbiol. 2005;71:3544-50 American Society for Microbiology; [cited 2019 Jul 9]. Available from: http://www.ncbi.nlm.nih. gov/pubmed/16000760.

56. Eckert W, Frevert T, Dan TB-B, Cavari BZ. Competitive development of Thiocapsa roseopersicina and Chlorobium phaebacteroides in Lake Kinneret. Can J Microbiol. 1986;32:917-21 NRC Research Press Ottawa, Canada ; [cited 2019 Jul 9]. Available from: http://www.nrcresearchpress.com/doi/10.1139/m86-169.

57. Findlay AJ, Bennett AJ, Hanson TE, Luther GW. Light-dependent sulfide oxidation in the anoxic zone of the chesapeake bay can be explained by small populations of phototrophic bacteria. Appl Environ Microbiol. 2015;81: 7560-9 Available from: http://aem.asm.org/content/81/21/7560.abstract.

58. Herbert RA, Tanner AC. The isolation and some characteristics of photosynthetic bacteria (Chromatiaceae and Chlorobiaceae) from Antarctic marine sediments. J Appl Bacteriol. 1977;43:437-45. Available from:. https:// doi.org/10.1111/j.1365-2672.1977.tb00770.x.

59. Parkin TB, Brock TD. The effects of light quality on the growth of phototrophic bacteria in lakes. Arch Microbiol. 1980;125:19-27. Available from. https://doi.org/10.1007/BF00403193.

60. Manske AK, Glaeser J, Kuypers MMM, Overmann J. Physiology and phylogeny of green sulfur bacteria forming a Monospecific phototrophic assemblage at a depth of 100 meters in the Black Sea. Appl Environ Microbiol. 2005;71:8049-60 Available from: http://aem.asm.org/content/ 71/12/8049.abstract.

61. Máthé I, Borsodi AK, Tóth EM, Felföldi T, Jurecska L, Krett G, et al. Vertical physico-chemical gradients with distinct microbial communities in the hypersaline and heliothermal Lake Ursu (Sovata, Romania). Extremophiles. 2014;18:501-14. Available from. https://doi.org/10.1007/s00792-014-0633-1.

62. Gregersen LH, Habicht KS, Peduzzi S, Tonolla M, Canfield DE, Miller M, et al. Dominance of a clonal green sulfur bacterial population in a stratified lake. FEMS Microbiol Ecol. 2009;70:30-41. Available from:. https://doi.org/10.1111/ j.1574-6941.2009.00737.x

63. Armitage DW, Gallagher KL, Youngblut ND, Buckley DH, Zinder SH. Millimeterscale patterns of phylogenetic and trait diversity in a salt marsh microbial mat. Front Microbiol. 2012;3:293 Frontiers; [cited 2019 Mar 20]Available from: http:// journal.frontiersin.org/article/10.3389/fmicb.2012.00293/abstract.

64. Pierson B, Oesterle A, Murphy GL. Pigments, light penetration, and photosynthetic activity in the multi-layered microbial mats of great Sippewissett salt marsh, Massachusetts. FEMS Microbiol Lett. 1987;45:365-76.

65. Nicholson JAM, Stolz JF, Pierson BK. Structure of a microbiol mat at great Sippewissett marsh, Cape Cod, Massachusetts. FEMS Microbiol Lett. 1987:45: 343-64. 
66. Bolhuis H, Cretoiu MS, Stal LJ. Molecular ecology of microbial mats. FEMS Microbiol Ecol. 2014;90:335-50 Oxford University Press; [cited 2019 Mar 20]. Available from: https://academic.oup.com/femsec/article/90/2/335/2680422/ Molecular-ecology-of-microbial-mats.

67. Bolhuis H, Stal LJ. Analysis of bacterial and archaeal diversity in coastal microbial mats using massive parallel 165 rRNA gene tag sequencing. ISME J. 2011;5:1701-12. International Society for Microbial Ecology; Available from:. https://doi.org/10.1038/ismej.2011.52.

68. Gregersen LH, Bryant DA, Frigaard N-U. Mechanisms and evolution of oxidative sulfur metabolism in green sulfur bacteria. Front Microbiol. 2011;2: 116 Frontiers; [cited 2019 Oct 19]. Available from: http://journal.frontiersin. org/article/10.3389/fmicb.2011.00116/abstract.

69. Dahl C. Sulfur metabolism in phototrophic bacteria. Cham: Springer International Publishing; 2017. p. 27-66. Mod Top Phototrophic Prokaryotes. [cited 2019 Oct 19]. Available from: http://link.springer.com/10.1007/ 978-3-319-51365-2_2

70. Hamilton TL, Bovee RJ, Thiel V, Sattin SR, Mohr W, Schaperdoth I, et al. Coupled reductive and oxidative sulfur cycling in the phototrophic plate of a meromictic lake. Geobiology. 2014;12:451-68 John Wiley \& Sons, Ltd (10.1111): [cited 2019 Jul 9]. Available from: http://doi.wiley.com/10.1111/gbi.12092.

71. Ogawa T, Furusawa T, Nomura R, Seo D, Hosoya-Matsuda N, Sakurai H, et al. SoxAX binding protein, a novel component of the thiosulfate-oxidizing multienzyme system in the green sulfur bacterium Chlorobium tepidum. J Bacteriol. 2008;190:6097-110 American Society for Microbiology Journals; [cited 2019 Jul 10]. Available from: http://www.ncbi.nlm.nih.gov/pubmed/1 8641134.

72. Cotter PA, Chepuri V, Gennis RB, Gunsalus RP. Cytochrome o (cyoABCDE) and $d(c y d A B)$ oxidase gene expression in Escherichia coli is regulated by oxygen, $\mathrm{pH}$, and the fnr gene product. J Bacteriol. 1990;172:6333-8 American Society for Microbiology Journals; [cited 2019 Jul 10]. Available from: http://www.ncbi.nlm.nih.gov/pubmed/2172211.

73. Pringault $O$, Kühl M, De Wit R, Caumette $P$. Growth of green Sulphur bacteria in experimental benthic oxygen, sulphide, $\mathrm{pH}$ and light gradients. Microbiology. 1998;144:1051-61.

74. Llorens-Marès T, Liu Z, Allen LZ, Rusch DB, Craig MT, Dupont CL, et al. Speciation and ecological success in dimly lit waters: horizontal gene transfer in a green sulfur bacteria bloom unveiled by metagenomic assembly. ISME J. 2017;11:201-11.

75. Borton MA, Daly RA, O'Banion B, Hoyt DW, Marcus DN, Welch S, et al. Comparative genomics and physiology of the genus Methanohalophilus, a prevalent methanogen in hydraulically fractured shale. Environ Microbiol. 2018;20:4596-611.

76. Daly RA, Roux S, Borton MA, Morgan DM, Johnston MD, Booker AE, et al. Viruses control dominant bacteria colonizing the terrestrial deep biosphere after hydraulic fracturing. Nat Microbiol. 2019;4:352-61.

77. Daly RA, Borton MA, Wilkins MJ, Hoyt DW, Kountz DJ, Wolfe RA, et al. Microbial metabolisms in a 2.5-km-deep ecosystem created by hydraulic fracturing in shales. Nat Microbiol. 2016;1:16146. Macmillan Publishers Limited; Available from:. https://doi.org/10.1038/nmicrobiol.2016.146.

78. Goodcare N, Aljanahi A, Nandakumar S, Mikailov M, Khan AS. A reference viral database (RVDB) to enhance bioinformatics analysis of high-throughput sequencing for novel virus detection. mSphere. 2018;3:1-18.

79. Stookey LL. Ferrozine---a new spectrophotometric reagent for iron. Anal Chem. 1970;42:779-81 American Chemical Society; [cited 2019 Feb 13]. Available from: http://pubs.acs.org/doi/abs/10.1021/ac60289a016.

80. Cline JD. Spectrophotometric determination of hydrogen sulfide in natural waters. Limnol Oceanogr. 1969;14:454-8.

81. Morrison HG, Grim SL, Vineis JH, Mitchell LS. 165 amplicon fusion primers and protocol for Illumina platform sequencing. 2013. Available from: https:// figshare.com/articles/16S_amplicon_fusion_primers_and_protocol_for_ Illumina_platform_sequencing/833944

82. Schloss PD, Westcott SL, Ryabin T, Hall JR, Hartmann M, Hollister EB, et al. Introducing mothur: open-source, platform-independent, communitysupported software for describing and comparing microbial communities. Appl Environ Microbiol. 2009;75:7537-41.

83. Martin M. Cutadapt removes adapter sequences from high-throughput sequencing reads. EMBnet.journal. 2011;17:10 [cited 2019 Feb 25]. Available from: http://journal.embnet.org/index.php/embnetjournal/article/view/200.

84. Callahan BJ, McMurdie PJ, Rosen MJ, Han AW, Johnson AJA, Holmes SP. DADA2: High-resolution sample inference from Illumina amplicon data. Nat Methods. 2016;13:581-3. Nature Publishing Group, a division of Macmillan
Publishers Limited. All Rights Reserved.; Available from. https://doi.org/10. 1038/nmeth.3869.

85. Quast C, Pruesse E, Yilmaz P, Gerken J, Schweer T, Yarza P, et al. The SILVA ribosomal RNA gene database project: improved data processing and webbased tools. Nucleic Acids Res. 2013;41:D590-6 Available from: http://nar. oxfordjournals.org/content/41/D1/D590.abstract.

86. Wickham H. stringr: Simple, Consistent Wrappers for Common String Operations; 2018.

87. Wickham H. ggplot2: elegant graphics for data analysis. [internet]. New York: Springer-Verlag New York; 2009. Available from: http://ggplot2.org

88. Oksanen J, Blanchet FG, Kindt R, Legendre P, Minchin PR, O'Hara RB, et al. vegan: Community Ecology Package. 2012; Available from: http://cran.rproject.org/package=vegan

89. Roberts DW. labdsv: Ordination and Multivariate Analysis for Ecology. 2012. Available from: http://cran.r-project.org/package=labdsv

90. Conway JR, Lex A, Gehlenborg N. UpSetR: An R package for the visualization of intersecting sets and their properties. bioRxiv. 2017; Available from: http://biorxiv.org/content/early/2017/03/25/120600.abstract.

91. Wickham H, François R, Henry L, Müller K. dplyr: A grammar of data manipulation; 2018.

92. Hill TCJ, Walsh KA, Harris JA, Moffett BF. Using ecological diversity measures with bacterial communities. FEMS Microbiol Ecol. 2003:43:1-11.

93. Schmieder R, Edwards R. Quality control and preprocessing of metagenomic datasets. Bioinformatics. 2011;27:863-4 Oxford University Press; [cited 2019 Feb 4]. Available from: http://www.ncbi.nlm.nih.gov/ pubmed/21278185.

94. Bankevich A, Nurk S, Antipov D, Gurevich AA, Dvorkin M, Kulikov AS, et al. SPAdes: a new genome assembly algorithm and its applications to singlecell sequencing. J Comput Biol. 2012;19:455-77.

95. Kang DD, Froula J, Egan R, Wang Z. MetaBAT, an efficient tool for accurately reconstructing single genomes from complex microbial communities. PeerJ. 2015;3:e1165 PeerJ Inc.; [cited 2019 Feb 14]. Available from: https://peerj. com/articles/1165.

96. Eren AM, Esen ÖC, Quince C, Vineis JH, Morrison HG, Sogin ML, et al. Anvi'o: an advanced analysis and visualization platform for 'omics data. PeerJ. 2015; 3:e1319 PeerJ Inc.; [cited 2019 Feb 14]. Available from: https://peerj.com/ articles/1319.

97. Parks DH, Imelfort M, Skennerton CT, Hugenholtz P, Tyson GW. CheckM: assessing the quality of microbial genomes recovered from isolates, single cells, and metagenomes. Genome Res. 2015;25:1043-55 s.

98. Silva GGZ, Cuevas D a, Dutilh BE, Edwards $R$ a. FOCUS: an alignment-free model to identify organisms in metagenomes using non-negative least squares. PeerJ. 2014;2:e425

99. Wattam AR, Davis JJ, Assaf R, Boisvert S, Brettin T, Bun C, et al. Improvements to PATRIC, the all-bacterial bioinformatics database and analysis resource center. Nucleic Acids Res. 2017:45:D535-42.

100. Couvin D, Bernheim A, Toffano-Nioche C, Touchon M, Michalik J, Néron B, et al. CRISPRCasFinder, an update of CRISRFinder, includes a portable version, enhanced performance and integrates search for Cas proteins. Nucleic Acids Res. 2018;46:W246-51 Oxford University Press; [cited 2019 Feb 14]Available from: https://academic.oup.com/nar/article/46/W1/W246/5 001162.

101. Zhang Q, Ye Y. Not all predicted CRISPR-Cas systems are equal: isolated cas genes and classes of CRISPR like elements. BMC Bioinformatics. 2017;18:92 BioMed Central; [cited 2019 Feb 14]. Available from: http://www.ncbi.nlm. nih.gov/pubmed/28166719.

102. Langmead B, Salzberg SL. Fast gapped-read alignment with Bowtie 2. Nat Methods. 2012;9:357. Nature Publishing Group, a division of Macmillan Publishers Limited. All Rights Reserved.. Available from. https://doi.org/10. 1038/nmeth.1923.

103. Meyer F, Paarmann D, D'Souza M, Olson R, Glass EM, Kubal M, et al. The metagenomics RAST server - a public resource for the automatic phylogenetic and functional analysis of metagenomes. BMC Bioinformatics. 2008;9:1-8. Available from:. https://doi.org/10.1186/1471-2105-9-386.

\section{Publisher's Note}

Springer Nature remains neutral with regard to jurisdictional claims in published maps and institutional affiliations. 